\title{
IN VITRO CO-CULTURE AND EX VIVO ORGAN CULTURE ASSESSMENT OF PRIMED AND CRYOPRESERVED STROMAL CELL MICROCAPSULES FOR INTERVERTEBRAL DISC REGENERATION
}

\author{
S.M. Naqvi ${ }^{1,2}$, J. Gansau $^{1,2}$, D. Gibbons ${ }^{1,3}$ and C.T. Buckley ${ }^{1,2,4,5, *}$ \\ ${ }^{1}$ Trinity Centre for Bioengineering, Trinity Biomedical Sciences Institute, Trinity College Dublin, \\ The University of Dublin, Dublin, Ireland \\ ${ }^{2}$ School of Engineering, Trinity College Dublin, The University of Dublin, Dublin, Ireland \\ ${ }^{3}$ School of Medicine, Trinity College Dublin, The University of Dublin, Dublin, Ireland \\ ${ }^{4}$ Advanced Materials and Bioengineering Research (AMBER) Centre, Royal College of Surgeons in Ireland \\ and Trinity College Dublin, The University of Dublin, Dublin, Ireland \\ ${ }^{5}$ Tissue Engineering Research Group, Department of Anatomy, Royal College of Surgeons in Ireland, \\ 123 St. Stephens Green, Dublin, Ireland
}

\begin{abstract}
Priming towards a discogenic phenotype and subsequent cryopreservation of microencapsulated bone marrow stromal cells (BMSCs) may offer an attractive therapeutic approach for disc repair. It potentially obviates the need for in vivo administration of exogenous growth factors, otherwise required to promote matrix synthesis, in addition to providing 'off-the-shelf' availability. Cryopreserved and primed BMSC microcapsules were evaluated in an in vitro surrogate co-culture model system with nucleus pulposus (NP) cells under intervertebral disc (IVD)-like culture conditions and in an ex vivo bovine organ culture disc model.

BMSCs were microencapsulated in alginate microcapsules and primed for $14 \mathrm{~d}$ with transforming growth factor beta-3 (TGF- $\beta 3$ ) under low oxygen conditions prior to cryopreservation. For the in vitro phase, BMSC microcapsules (unprimed or primed) were cultured for $28 \mathrm{~d}$ in a surrogate co-culture model system mimicking that of the IVD. For the ex vivo phase, microcapsules (unprimed or primed) were injected into the NP of bovine discs that underwent nucleotomy.

In vitro results revealed that although NP cells produced significantly more matrix components in co-culture with BMSC microcapsules regardless of the differentiation state, unprimed microcapsules were inadequate at synthesising matrix as compared to primed microcapsules. However, this difference was diminished when evaluated in the ex vivo organ culture model, with both unprimed and primed BMSC microcapsules accumulating large amounts of sulphated glycosaminoglycan (sGAG) and collagen and filling the defect cavity. Both models demonstrated that cryopreservation of BMSC microcapsules may offer a feasible strategy for predesigned delivery through cryobanking for on-demand regeneration of the IVD.
\end{abstract}

Keywords: Degeneration, intervertebral disc, nucleus pulposus, mesenchymal stromal cells, bone marrow, in vitro, ex vivo, model system, priming, cryopreservation.

*Address for correspondence: Conor T. Buckley, Trinity Centre for Bioengineering, Trinity Biomedical Sciences Institute, Trinity College Dublin, Dublin, Ireland.

Telephone number: +353 18962061 Fax number: +353 6795554 Email: conor.buckley@tcd.ie

Copyright policy: This article is distributed in accordance with Creative Commons Attribution Licence (http://creativecommons.org/licenses/by-sa/4.0/).

\section{Introduction}

Cellular microencapsulation is a promising approach to repair the degenerated central nucleus pulposus (NP) region of the intervertebral disc (IVD) in a minimally invasive manner (Wang et al., 2013). A method to microencapsulate cells is by using electrohydrodynamic atomisation (EHDA) (Bartolovic et al., 2010; Jayasinghe, 2007;
Jayasinghe, 2011; Jayasinghe et al., 2006; Naqvi et al., 2016; Workman et al., 2014). By passing a polymer-containing cell solution through a needle subjected to a potential difference, this technique allows the fabrication of micron-sized capsules upon subsequent crosslinking (Gasperini et al., 2013). These cell-encapsulated microcapsules may be injected into the central NP. With respect to the cell type, mesenchymal stromal cells (MSCs) are 
proposed as a potential cell source for promoting NP repair (Risbud et al., 2004; Sakai et al., 2003; Steck et al., 2005; Stoyanov et al., 2011). However, in their undifferentiated state, MSCs require the concurrent delivery of growth factors in order to differentiate towards a discogenic phenotype. Naqvi et al. (2018) show that primed bone marrow stromal cell (BMSC) microcapsules [BMSC microcapsules cultured for $14 \mathrm{~d}$ in transforming growth factor beta-3 (TGF-33)supplemented medium to direct differentiation] maintain their potential to synthesise NP-like matrix components in vitro post-cryopreservation in the absence of growth factor supplementation. The same study has verified cell survival after cryopreservation and injection through a $25 \mathrm{G}$ needle, providing the motivation for further development of microcapsules for the treatment of disc degeneration. Thus, this approach may offer the possibility of predesigned deliverability through cryobanking but requires testing in appropriate model systems prior to clinical translation.

In this respect, in vitro co-culture models are convenient as they offer a means for research on cellto-cell communications, repair and regeneration. In co-culture systems, two or more cell types are cultured together, to recapitulate the typical in vivo cellular interactions. Signalling between NP cells and MSCs occurs, leading to matrix synthesis and enhanced NP proliferation (Le Visage et al., 2006; Richardson et al., 2006; Vadala et al., 2008; Yamamoto et al., 2004). However, current co-culture model investigations have been unable to identify the cell type responsible for matrix synthesis within the system. A previous study suggests that in indirect co-culture, MSCs act as supporting cells promoting proliferation and matrix production (Naqvi and Buckley, 2015a). Nonetheless, there are uncertainties as of the exact mechanism by which MSCs stimulate repair (Gaetani et al., 2008; Le Visage et al., 2006; Richardson et al., 2006; Strassburg et al., 2010; Vadala et al., 2008; Yamamoto et al., 2004). Specifically, it is unknown whether repair is a result of differentiation of the injected MSCs towards a discogenic phenotype and/or some form of a stimulatory effect on the resident degenerated NP cells. To address these issues, a structured idealised co-culture model system, where both cell types may be analysed separately after the co-culture, may be advantageous to investigate each cell type in isolation.

Ex vivo organ culture systems have gained significant attention to assess and validate potential therapeutic strategies, with bovine caudal discs providing a suitable and acceptable model for many studies of the IVD (Bucher et al., 2013; Chan et al., 2010; Chan et al., 2013; Furtwangler et al., 2013; Oshima et al., 1993). Previous studies use these models for investigations as they have similar physico-chemical properties, composition (types and distributions of aggrecan and collagen), metabolism, function, regulation and biomechanics (in vitro proteoglycan synthesis rates and matrix synthesis responses to hydrostatic pressure) to human discs (Aguiar et al., 1999; Errington et al., 1998; Gahunia et al., 2002; Horner et al., 2002; Horner and Urban, 2001; Ishihara et al., 1996; Ishihara et al., 1997; Nerlich et al., 1997; Oegema et al., 2000; Ohshima and Urban, 1992; Ohshima et al., 1995; Oloyede et al., 1998; Oshima et al., 1993; Race et al., 2000; Razaq et al., 2000; Roberts et al., 1995; Roberts et al., 1991; Simunic et al., 2001). Moreover, the structure of the bovine disc is similar to the young healthy human IVD and the swelling pressure of bovine coccygeal IVDs has the same magnitude as that of human discs in humans resting in a prone position (Ishihara et al., 1996; Oshima et al., 1993).

The overall objective of the present study was to assess the potential of primed and cryopreserved BMSC-encapsulated microcapsules in two different model systems: in vitro co-culture and ex vivo organ culture. The specific aims were to identify which cell type was responsible for matrix synthesis in an in vitro co-culture model and whether an ex vivo model better informed the investigator of the potential of such a therapy. The potential of using cryopreserved primed BMSC microcapsules was evaluated in an in vitro co-culture model system with NP cells. The NP is a glucose- and oxygen-deprived tissue, since the closest blood vessel can be up to $8 \mathrm{~mm}$ away (Katz et al., 1986; Urban et al., 1982). In particular, a major biochemical change that occurs during IVD degeneration is the accumulation of lactic acid (Katz et al., 1986; Urban et al., 1982; Urban et al., 2004) and the concomitant increase in matrix acidity (Bartels et al., 1998; Buckwalter, 1995; Diamant et al., 1968; Keshari et al., 2008; Rajasekaran et al., 2010). As such, in vitro cultures were maintained under both low glucose (5 mM) and low oxygen (5\%) concentrations and mildly degenerated IVD-like $\mathrm{pH}$ conditions ( $\mathrm{pH}$ 6.8). Importantly, a structured idealised co-culture model system was developed where both cell types could be analysed separately after the co-culture period. Also, the potential of using cryopreserved primed BMSC microcapsules was evaluated in an ex vivo model system using bovine discs.

\section{Materials and Methods}

\section{NP cell isolation and culture}

IVDs from the lumbar region were harvested from the spine of porcine donors (3-5 months, 30-50 kg) within $3 \mathrm{~h}$ of sacrifice. Under aseptic conditions, IVDs were carefully exposed and the gelatinous NP removed from the central section of the disc (Naqvi and Buckley, 2015a). To confirm the absence of bacterial growth, dissected tissue was cultured overnight at $37{ }^{\circ} \mathrm{C}, 5 \% \mathrm{CO}_{2}$ in a humidified atmosphere in serum-free low-glucose Dulbecco's modified Eagle's medium (LG-DMEM, 1 g/L D-glucose) supplemented with antibiotics/antimycotics $(100 \mathrm{U} / \mathrm{mL}$ penicillin, $100 \mu \mathrm{g} / \mathrm{mL}$ streptomycin). The NP was enzymatically digested in a $2.5 \mathrm{mg} / \mathrm{mL}$ pronase solution for $1 \mathrm{~h}$ 
followed by $4 \mathrm{~h}$ in $0.5 \mathrm{mg} / \mathrm{mL}$ collagenase solution at $37^{\circ} \mathrm{C}$ under constant rotation in serum-free LGDMEM containing antibiotic/antimycotics $(100 \mathrm{U} / \mathrm{mL}$ penicillin, $100 \mu \mathrm{g} / \mathrm{mL}$ streptomycin). Digested tissue/ cell suspension was passed through a $100 \mu \mathrm{m}$ cell strainer to remove tissue debris followed by $70 \mu \mathrm{m}$ and $40 \mu \mathrm{m}$ cell strainers to separate notochordal cells (NC) from the desired NP cells, as previously described (Spillekom et al., 2014). Cells were washed three times by repeated centrifugation at $650 \times g$ for $5 \mathrm{~min}$. NP cells were cultured to confluence at $37^{\circ} \mathrm{C}$, $5 \% \mathrm{CO}_{2}$ in a humidified atmosphere in T-75 flasks with LG-DMEM supplemented with $10 \%$ foetal bovine serum (FBS), $100 \mathrm{U} / \mathrm{mL}$ penicillin, $100 \mu \mathrm{g} / \mathrm{mL}$ streptomycin (all GIBCO), $2.5 \mu \mathrm{g} / \mathrm{mL}$ amphotericin B (Sigma-Aldrich), $5 \mathrm{ng} / \mathrm{mL}$ fibroblast growth factor-2 (FGF-2; PeproTech) and expanded to passage 2 (P2) with medium exchanges performed every 3-4 $\mathrm{d}$.

\section{BMSC isolation and monolayer expansion}

Donor-matched porcine BMSCs were isolated and maintained as previously described (Naqvi and Buckley, 2015a). Briefly, mononuclear cells were isolated from the femora of porcine donors (3-5 months, 30-50 kg) within $2 \mathrm{~h}$ of sacrifice and plated at a density of $10 \times 10^{6}$ cells in T-75 flasks to allow for colony formation. MSCs were maintained in LG-DMEM supplemented with 10 \% FBS, 100 U/ $\mathrm{mL}$ penicillin, $100 \mu \mathrm{g} / \mathrm{mL}$ streptomycin and $0.25 \mu \mathrm{g} /$ $\mathrm{mL}$ amphotericin B. Cultures were washed with phosphate-buffered saline (PBS) after $72 \mathrm{~h}$. When passaged, BMSCs were plated at a density of $5 \times 10^{3}$ cells $/ \mathrm{cm}^{2}$ and expanded to P2 in a humidified atmosphere at $37^{\circ} \mathrm{C}$ and $5 \% \mathrm{CO}_{2}$.

Fabrication of BMSC microcapsules using EHDA BMSCs were trypsinised and counted using trypan blue exclusion and, subsequently, resuspended in medium consisting of LG-DMEM supplemented with $10 \%$ FBS, $100 \mathrm{U} / \mathrm{mL}$ penicillin, $100 \mu \mathrm{g} / \mathrm{mL}$ streptomycin and $0.25 \mu \mathrm{g} / \mathrm{mL}$ amphotericin B. The cell suspension was mixed with $2 \%$ alginate (Pronova UP LVG; FMC NovaMatrix, Sandvika, Norway) dissolved in PBS at a ratio of $1: 1$, to yield a final alginate concentration of $1 \%$ and a cell density of $20 \times 10^{6}$ cells $/ \mathrm{mL}$. A Spraybase ${ }^{\circledR}$ electrosprayer (Profector Life Sciences, Dublin, Ireland) was used to produce the microcapsules. Briefly, the cell/ alginate mixture was passed through a $26 \mathrm{G}$ needle into a collecting dish containing $102 \mathrm{mM} \mathrm{CaCl}_{2}$ solution using a syringe pump (pump speed: $100 \mu \mathrm{L}$ ) min) while applying a voltage of $10 \mathrm{kV}$ to yield microcapsules with a diameter $(\varnothing)$ of $240 \pm 22.04 \mu \mathrm{m}$. Microcapsules were allowed to fully crosslink for 15 min and washed with PBS prior to resuspension in the appropriate medium for culture.

\section{In vitro priming and cryopreservation of the microcapsules}

Post-fabrication, $150 \mu \mathrm{L}$ of BMSC microcapsules $\left(3 \times 10^{6}\right.$ cells $)$ were transferred into each well of a 6-well plate and maintained in $10 \mathrm{~mL}$ of LGDMEM supplemented with $40 \mu \mathrm{g} / \mathrm{mL}$ L-proline, $100 \mathrm{nM}$ dexamethasone, $50 \mu \mathrm{g} / \mathrm{mL}$ L-absorbic acid 2-phosphate, $4.7 \mu \mathrm{g} / \mathrm{mL}$ linoleic acid (all Sigma-Aldrich), $100 \mathrm{U} / \mathrm{mL}$ penicillin, $100 \mu \mathrm{g} / \mathrm{mL}$ streptomycin, $0.25 \mu \mathrm{g} / \mathrm{mL}$ amphotericin $\mathrm{B}$ and 10 ng/mL TGF- $\beta 3$ (PeproTech). Microcapsules were cultured in low oxygen $\left(5 \% \mathrm{O}_{2}\right)$ conditions for $14 \mathrm{~d}$ and medium was exchanged twice weekly. Of note, medium exchanges were not performed under low oxygen. However, primed groups were exposed to atmospheric oxygen only minimally by performing medium changes as quickly as possible and one plate at a time. Unprimed microcapsules served as control.

Post-fabrication or post-priming, $150 \mu \mathrm{L}$ of BMSC microcapsules were resuspended in $1 \mathrm{~mL}$ of freezing medium consisting of $90 \%$ FBS and $10 \%$ DMSO (final cell density: $3 \times 10^{6}$ cells $/ \mathrm{mL}$ ) and transferred to cryovials (CryoPure, $2.0 \mathrm{~mL}$, Sarstedt), as previously described (Naqvi et al., 2018). Vials were placed in a cryogenic freezing container (5100-0001 PC/HDPE, Mr. Frosty ${ }^{\mathrm{TM}}$; Nalgene), stored at $-85^{\circ} \mathrm{C}$ overnight and, subsequently, stored in liquid nitrogen. When required, vials were thawed in a water bath $\left(37^{\circ} \mathrm{C}\right)$ for $2 \mathrm{~min}$ and, then, $10 \mathrm{~mL}$ of LG-DMEM supplemented with $10 \%$ FBS, $100 \mathrm{U} / \mathrm{mL}$ penicillin, $100 \mu \mathrm{g} / \mathrm{mL}$ streptomycin and $0.25 \mu \mathrm{g} / \mathrm{mL}$ amphotericin B were added drop by drop over 2 min.

\section{In vitro co-culture model system}

Upon thawing, $60 \mu \mathrm{L}$ of cryopreserved primed microcapsules were cultured in a structured coculture model system (Fig. 1a). Microcapsules were encompassed by a ring [inner $\varnothing=5 \mathrm{~mm}$, outer $\varnothing=9 \mathrm{~mm}$, height $(\mathrm{H})=3 \mathrm{~mm}$ ] of NP cells encapsulated in alginate. Briefly, NP cells were encapsulated in $1.5 \%$ alginate in isolation at a cell density of $4 \times 10^{6}$ cells $/ \mathrm{mL}$. Alginate/cell suspensions were ionically crosslinked with $102 \mathrm{mM} \mathrm{CaCl}_{2}$ for $30 \mathrm{~min}$ to form cylindrical constructs (outer $\varnothing=9 \mathrm{~mm}$, $\mathrm{H}=3 \mathrm{~mm}$ ). A $5 \mathrm{~mm}$ biopsy punch was used to create a well of $5 \mathrm{~mm}$ in diameter in the centre of the construct, resulting in a ring (inner $\varnothing=5 \mathrm{~mm}$, outer $\varnothing=9 \mathrm{~mm}, \mathrm{H}=3 \mathrm{~mm}$ ) which was press-fit into an agarose mould. Constructs were maintained in a flat-bottomed tube $(8 \mathrm{~mL}, 57 \times 16.5 \mathrm{~mm}$, Sarstedt $)$ for the entire culture period. Cultures were maintained at $37{ }^{\circ} \mathrm{C}$ for $28 \mathrm{~d}$ under low glucose $(5 \mathrm{mM})$ and low oxygen $(5 \%)$ conditions without exogenous growth factor supplementation. In addition, two $\mathrm{pH}$ microenvironments were explored: standard ( $\mathrm{pH}$ 7.4) and simulated IVD-like ( $\mathrm{pH}$ 6.8) conditions (Wuertz et al., 2008). To adjust the $\mathrm{pH}$ value to 6.8, $10 \mu \mathrm{L} / \mathrm{mL}$ of $2 \mathrm{M} \mathrm{HCl}$ was added to the medium and allowed to equilibrate in a humidified hypoxic incubator overnight. Standard medium was also maintained under similar conditions overnight (Naqvi and Buckley, 2016). Medium consisted of LG-DMEM supplemented with $100 \mathrm{U} / \mathrm{mL}$ penicillin, $100 \mu \mathrm{g} / \mathrm{mL}$ streptomycin, $0.25 \mu \mathrm{g} / \mathrm{mL}$ amphotericin $\mathrm{B}, 1.5 \mathrm{mg} / \mathrm{mL}$ bovine serum albumin 
(BSA, Sigma-Aldrich), $1 \times$ insulin-transferrin-sodium selenite (ITS; Sigma-Aldrich), $40 \mu \mathrm{g} / \mathrm{mL}$ L-proline, $100 \mathrm{nM}$ dexamethasone, $50 \mu \mathrm{g} / \mathrm{mL}$ L-ascorbic acid 2-phosphate and $4.7 \mu \mathrm{g} / \mathrm{mL}$ linoleic acid. For comparison, cryopreserved unprimed microcapsules were cultured under identical conditions. Each tube was maintained in $2 \mathrm{~mL}$ of medium with half medium exchanges performed every 3-4 $\mathrm{d}$.

\section{Ex vivo culture of microcapsules}

Skeletally mature bovine tails (<30 months) were obtained from a local abattoir and cut proximally and distally to the endplates (EP) with a custom-made guillotine. Blood clots and bone debris were removed by flushing the endplates with PBS using a custommade irrigation system. Then, caudal discs were rinsed in PBS containing $100 \mathrm{U} / \mathrm{mL}$ penicillin, $100 \mu \mathrm{g} /$
$\mathrm{mL}$ streptomycin and $0.25 \mu \mathrm{g} / \mathrm{mL}$ amphotericin $\mathrm{B}$ and assigned to the following groups: day 0 control, empty nucleotomy control, healthy control, nucleotomy with primed BMSC microcapsules (treatment) and nucleotomy with unprimed BMSC microcapsules (comparison treatment). Nucleotomies were created by performing a cruciate cut with a \#15 scalpel into the centre of the disc (Fig. 1b, II). Tissue was loosened and removed using the enSpire ${ }^{\mathrm{TM}}$ MicroDiscectomy System (SpineView, Inc., Fremont, CA, USA) (Fig. 1b, III). After partial nucleotomy, $500 \mu \mathrm{L}$ of unprimed or primed microcapsules in LG-DMEM supplemented with $10 \%$ FBS, 100 U/mL penicillin, $100 \mu \mathrm{g} / \mathrm{mL}$ streptomycin and $0.25 \mu \mathrm{g} / \mathrm{mL}$ amphotericin B were injected into the created defects with a high-precision syringe and needle (Hamilton gastight syringe, model 1750; 20G metal hub custom

\section{a In vitro co-culture model system}

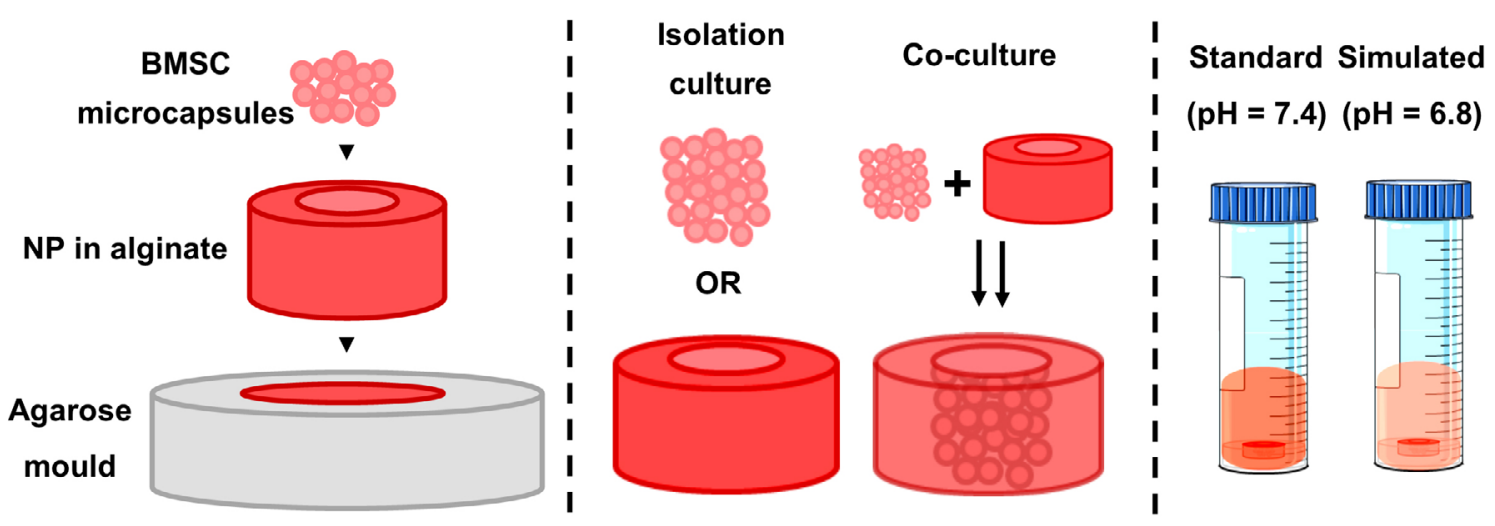

b Ex vivo co-culture model system

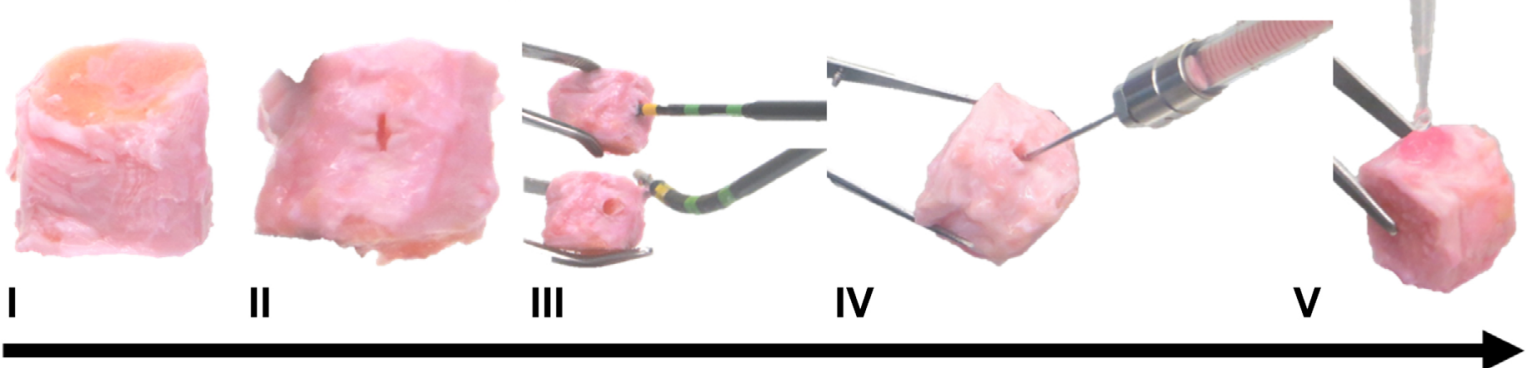

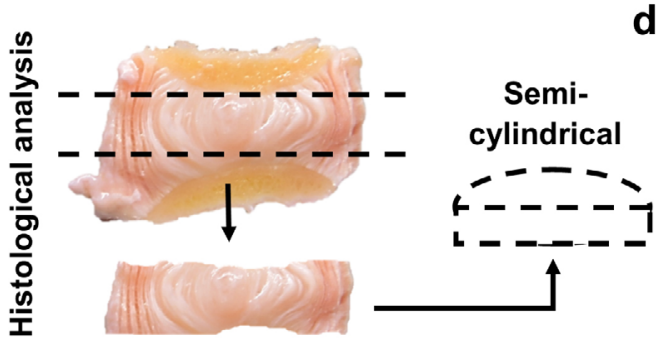

d

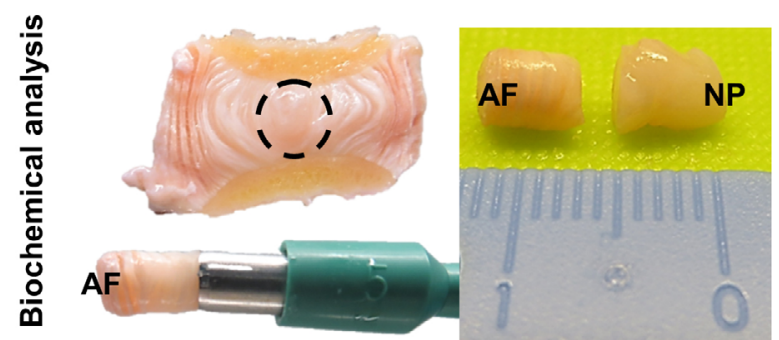

Fig. 1. Experimental Design. (a) Schematic illustrating in vitro co-culture model system showing isolation culture and co-culture configurations and pH conditions. (b) Ex vivo organ model system - bovine disc preparation; I: IVDs were harvested from skeletally mature bovine tails, II: nucleotomies were created by performing a cruciate cut with a \#15 scalpel to the centre of the IVD, III: tissue was removed using the enSpire ${ }^{\mathrm{TM}}$ MicroDiscectomy System, IV: $500 \mu \mathrm{L}$ of unprimed or primed microcapsules were injected into the injury site of treated IVDs using a high-precision syringe, V: the AF was closed using a fibrin glue. (c) Illustration showing semi-cylindrical sample used for histology. (d) Illustration showing $\varnothing=5 \mathrm{~mm} \times \mathrm{H}=5 \mathrm{~mm}$ NP samples used for biochemical analyses. 
needle) (Fig. 1b, IV). The annulus fibrosus (AF) was subsequently sealed using a fibrin glue $(50 \mathrm{mg} / \mathrm{mL}$ final fibrin, $5 \mathrm{U} / \mathrm{mL}$ thrombin, both Sigma-Aldrich) (Fig. 1b, V). Discs were cultured for $28 \mathrm{~d}$ in $100 \mathrm{~mL}$ of high-glucose DMEM (HG-DMEM) supplemented with $10 \%$ FBS, $100 \mathrm{U} / \mathrm{mL}$ penicillin, $100 \mu \mathrm{g} / \mathrm{mL}$ streptomycin, $0.25 \mu \mathrm{g} / \mathrm{mL}$ amphotericin $B, 1.5 \mathrm{mg} / \mathrm{mL}$ $\mathrm{BSA}$ and $40 \mu \mathrm{g} / \mathrm{mL}$ L-proline under gentle agitation (orbital platform shaker, PSU-10i, Biosan, Riga, Latvia) at $37^{\circ} \mathrm{C}$ in normoxic ( $20 \%$ oxygen) conditions, with medium changed twice weekly.

\section{Processing of bovine discs for assessment}

After culture, the endplates were removed and the discs were cut in half in the sagittal plane. For histological analysis, a custom-made guillotine was used to remove the vertebral body, including the EP, either side of the disc (Fig. 1c). The remaining semi-cylindrical shaped tissue was dehydrated and paraffin-wax-embedded. For biochemical analysis, a $5 \mathrm{~mm}$ biopsy punch was used to core the central NP through the AF (Fig. 1d). The NP and AF regions were separated using a scalpel. The NP $(\varnothing=5 \mathrm{~mm}$, $\mathrm{H}=5 \mathrm{~mm}$ ) was frozen for subsequent biochemical analysis. Only a limited amount of NP tissue was available in the empty nucleotomy control after $28 \mathrm{~d}$ of culture and, therefore, it was excluded from further biochemical analyses.

\section{Cell viability}

Cell viability was assessed using a LIVE/DEAD ${ }^{\circledR}$ Viability/Cytotoxicity Kit (Invitrogen). Briefly, samples were washed in phenol-red-free medium followed by incubation in the medium containing $4 \mu \mathrm{m}$ calcein AM (live cell membrane) and $4 \mu \mathrm{m}$ ethidium homodimer-1 (dead cell DNA; both from Cambridge Bioscience, Cambridge, UK). Samples were washed in phenol-red-free medium, imaged with an Olympus FV-1000 confocal microscope using 515 and $615 \mathrm{~nm}$ channels and analysed using the FV10-ASW 3.1 software.

\section{Cell morphology}

Healthy, unprimed and primed microencapsulatedBMSC-treated bovine discs were stained for cell morphology after $28 \mathrm{~d}$ of whole organ culture. Briefly, slides were permeabilised using $0.5 \%$ Triton X-100 and stained with rhodamine phalloidin at $200 \mathrm{U} /$ $\mathrm{mL}$ (diluted 1:40; Sigma-Aldrich) to stain the actin cytoskeleton. 4',6'-diamidino-2-phenylindole (DAPI, diluted 1:500; Sigma-Aldrich) was used to stain the nucleus and rinsed with PBS. Subsequently, stained slides were imaged with a Leica SP8 scanning confocal at 358/524 and 540/565 nm wave-length (40× magnification) and assessed using the Leica Application Suit X (LAS X) software.

\section{Quantitative biochemical analysis}

Samples were digested with $3.88 \mathrm{U} / \mathrm{mL}$ papain in $0.1 \mathrm{M}$ sodium acetate, $5 \mathrm{mM}$ L-cysteine- $\mathrm{HCl}$ and $0.05 \mathrm{M}$ ethylenediaminetetraacetic acid (EDTA) (pH 6.0) (all from Sigma-Aldrich) at $60^{\circ} \mathrm{C}$ under constant rotation for $18 \mathrm{~h}$ followed by the addition of $1 \mathrm{M}$ sodium citrate solution for $1 \mathrm{~h}$ to dissociate crosslinked alginate. DNA content was determined using the Hoechst 33258 dye-based assay (DNA QF Kit; SigmaAldrich). Proteoglycan content was quantified using the dimethylmethylene blue dye-binding assay at pH 1.35 (Blyscan, Biocolor Ltd., Carrickfergus, Northern Ireland), with a chondroitin sulphate standard. Total collagen content was determined by measuring the hydroxyproline content. Samples were hydrolysed at $110^{\circ} \mathrm{C}$ for $18 \mathrm{~h}$ in $12 \mathrm{M} \mathrm{HCl}$ and assayed using a chloramine-T assay (Kafienah and Sims, 2004) with a hydroxyproline : collagen ratio of $1: 7.69$ (Ignat'eva et al., 2007). Baseline primed values were subtracted from day 28 values for the primed groups.

\section{Histology and immunohistochemistry}

At each time point, in vitro samples were fixed overnight in $4 \%$ paraformaldehyde, dehydrated in a graded series of ethanol, embedded in paraffin wax, sectioned at $8 \mu \mathrm{m}$ thickness and mounted on to microscope slides. Ex vivo samples were fixed in formalin for $72 \mathrm{~h}$ at room temperature and under constant agitation with formalin exchanges every $24 \mathrm{~h}$ before dehydration in a graded series of ethanol, embedded in paraffin wax, sectioned at $10 \mu \mathrm{m}$ thickness and mounted on to microscope slides. Both in vitro and ex vivo sections were stained with aldehyde fuchsin/alcian blue, to assess sulphated glycosaminoglycan (sGAG) content, and picrosirius red, to assess collagen distribution (all SigmaAldrich). Collagen types I and II were evaluated using a standard immunohistochemical technique, as described previously (Naqvi and Buckley, 2015a; Naqvi and Buckley, 2015b).

\section{Statistical analysis}

Statistical analyses were performed using GraphPad Prism (version 5) software with 3-4 samples analysed for each experimental group. The coculture experiment was replicated with cells from a second donor, which confirmed the findings of the present study. Two-way ANOVA was used for analysis of variance with Bonferroni's post-hoc test for comparison between groups. Graphical results are displayed as mean \pm standard deviation (SD). Significance was accepted at a level of $p<0.05$.

\section{Results}

\section{Co-culture inhibited cell proliferation as compared to isolation culture}

BMSC microcapsules exhibited significantly less DNA content as compared to day 0 , when DNA content was $9821 \pm 33.35 \mathrm{ng}$ and $6218.66 \pm 261.9 \mathrm{ng}$ in unprimed and primed BMSC microcapsules, respectively (data not shown). This reduction in DNA content from day 0 is attributed to cell death due to 
Table 1. Total DNA content (normalised to day 0 ) of in vitro cultures at day 28 . Unit $=\mathrm{ng} / \mathrm{ng} ; n=3$; mean \pm SD represented.

\begin{tabular}{|c|c|c|c|c|c|c|c|}
\hline & \multicolumn{4}{|c|}{ Isolation Culture } & \multicolumn{4}{c|}{ Co-culture } \\
\cline { 2 - 8 } & $\mathbf{N P}$ & Unprimed & Primed & NP & Unprimed & NP & Primed \\
\hline $\begin{array}{c}\text { Standard } \\
\text { (pH 7.4) }\end{array}$ & $0.62 \pm 0.01$ & $0.2 \pm 0.02$ & $0.67 \pm 0.02$ & $0.31 \pm 0.04$ & $0.14 \pm 0.04$ & $0.33 \pm 0.07$ & $0.46 \pm 0.4$ \\
\hline $\begin{array}{c}\text { Simulated } \\
\text { (pH 6.8) }\end{array}$ & $0.58 \pm 0.1$ & $0.09 \pm 0.04$ & $0.38 \pm 0.04$ & $0.36 \pm 0.02$ & $0.13 \pm 0.004$ & $0.4 \pm 0.12$ & $0.16 \pm 0.01$ \\
\hline
\end{tabular}

the highly metabolic nature of BMSCs, demanding larger amounts of glucose, and/or the EHDA spraying method, which may result in local stress concentrations causing cell damage (Naqvi et al., 2018). Furthermore, both microcapsule types yielded significantly less DNA in co-culture as compared to those cultured in isolation, irrespective of standard ( $\mathrm{pH}$ 7.4) or simulated conditions ( $\mathrm{pH}$ 6.8) (Fig. 2a and Table 1). Similar results were obtained for NP cells at the two different $\mathrm{pH}$ values (Table 1). Live/dead staining correlated with biochemical data illustrating fewer cells in co-culture groups (Fig. 2b).

Primed BMSC microcapsules cultured in isolation exhibited significantly larger DNA content $(p<0.01)$ when cultured in standard conditions as compared to simulated conditions. This was also observed for the same microcapsules co-cultured with NP cells (Fig. 2a). Live/dead staining also correlated with DNA data illustrating fewer cells in simulated conditions (Fig. 2b). For unprimed BMSC microcapsules cultured in isolation, there was also a significant difference between those cultured in standard and simulated conditions. Those in standard conditions contained more DNA (Fig. 2a). Live/dead staining illustrated similar findings with more dead cells observed in simulated conditions (Fig. 2b). Importantly, primed BMSC microcapsules contained significantly more DNA than unprimed BMSC microcapsules, with the exception of primed BMSC microcapsules cocultured with NP cells in simulated conditions.

\section{Co-culture model - sGAG accumulation \\ NP cells}

When compared to NP cells in isolation culture $[22.8 \pm 1.2 \mu \mathrm{g}$ (standard conditions) and $21 \pm 2.1 \mu \mathrm{g}$ (simulated conditions)], in co-culture with BMSC microcapsules, NP cells accumulated significantly larger amounts of sGAG with unprimed microcapsules under standard conditions $(32.2 \pm 4.3 \mu \mathrm{g})$ and with primed microcapsules under both standard and simulated conditions (42 $\pm 2 \mu \mathrm{g}$ and $40.3 \pm 3.2 \mu \mathrm{g}$, respectively) (Fig. 3a). This was also observed on a per cell basis when SGAG was normalised to normalised DNA content $(36.7 \pm 1.8 \mu \mathrm{g}, 36.9 \pm 4.2 \mu \mathrm{g}$ in isolation; $105.2 \pm 8.6 \mu \mathrm{g}, 60.3 \pm 6.3 \mu \mathrm{g}$ in unprimed co-culture; $129.7 \pm 21.6 \mu \mathrm{g}, 105.1 \pm 26.4 \mu \mathrm{g}$ in primed co-culture under standard and simulated conditions, respectively) (Fig. 3b). In fact, on a per cell basis,
NP cells accumulated significantly more sGAG in co-culture with unprimed microcapsules, for both standard and simulated conditions $(p<0.01)$. Histological staining for sGAG correlated with the biochemical data (Fig. 3c). The most noticeable sGAG deposition was observed in co-culture with primed BMSC microcapsules [Fig. 3c (f), (m)].

\section{BMSC microcapsules}

Unprimed BMSC microcapsules accumulated negligible amounts of sGAG in isolation and in co-culture with NP cells (Fig. 3a). Conversely, as compared to primed BMSC microcapsules cultured in isolation, those in co-culture with NP cells accumulated significantly less sGAG $(p<0.01)$, irrespective of standard or simulated conditions $(121 \pm 0.4 \mu \mathrm{g}, 95 \pm 1.6 \mu \mathrm{g}$ in isolation and $77.5 \pm 5.4 \mu \mathrm{g}$, $24.4 \pm 2.5 \mu \mathrm{g}$ in co-culture) (Fig. 3a). This was also observed when sGAG was normalised to DNA content $(182.4 \pm 5.3 \mu \mathrm{g}, 255.4 \pm 33.9 \mu \mathrm{g}$ in isolation; $169.3 \pm 4.4 \mu \mathrm{g}, 149 \pm 9.6 \mu \mathrm{g}$ in co-culture under standard and simulated conditions, respectively) (Fig. 3b).

When cultured in isolation and in co-culture, primed BMSC microcapsules accumulated significantly less sGAG in simulated conditions as compared to standard conditions. However, when normalised to DNA content, these differences were diminished and, in the case of primed BMSC microcapsules cultured in isolation, there was significantly more sGAG for primed BMSC microcapsules maintained in simulated culture conditions as compared to standard conditions (Fig. 3b). Histological staining for sGAG correlated with the biochemical findings (Fig. 3c). There was an obvious difference between unprimed and primed groups with little to no sGAG deposition in unprimed BMSC microcapsules [Fig. 3c - (b), (e), (i), (1)] and increased deposition in primed BMSC microcapsules [Fig. 3c-(c), (g), (j), (n)] cultured in isolation and in co-culture with NP.

\section{Co-culture model - collagen accumulation NP cells}

When compared to NP cells cultured in isolation $[7.4 \pm 1.4 \mu \mathrm{g} / \mu \mathrm{g}$ (standard conditions) and $8.1 \pm 1.8 \mu \mathrm{g} /$ $\mu \mathrm{g}$ (simulated conditions)], NP cells co-cultured with BMSC microcapsules accumulated more 
collagen under standard and simulated conditions (Fig. 4a,b) regardless of BMSC differentiation state $(38.1 \pm 13.3 \mu \mathrm{g} / \mu \mathrm{g}, 37.2 \pm 6.5 \mu \mathrm{g} / \mu \mathrm{g}$ in unprimed and $42.5 \pm 11 \mu \mathrm{g} / \mu \mathrm{g}, 35 \pm 10.9 \mu \mathrm{g} / \mu \mathrm{g}$ in primed). This difference was not significant on a $\mu \mathrm{g}$ basis but it was significant when collagen was normalised to DNA $(p<0.01)$ (Fig. 4b). Histological staining for collagen correlated with the biochemical findings (Fig. 4c). The most noticeable collagen deposition was observed for those co-cultured with primed BMSC microcapsules [Fig. $4 \mathrm{c}-(\mathrm{f}),(\mathrm{m})]$.

\section{BMSC microcapsules}

When compared to primed BMSC microcapsules cultured in isolation, those in co-culture with NP cells accumulated significantly less collagen $(p<0.01)$, irrespective of standard or simulated conditions $(73.4 \pm 0.9 \mu \mathrm{g}, 69.6 \pm 3.4 \mu \mathrm{g}$ in isolation vs. $23.3 \pm 4.2 \mu \mathrm{g}$, $13.76 \pm 1.6 \mu \mathrm{g}$ in co-culture, respectively) (Fig. 4a). When normalised to DNA content, significantly larger amounts $(p<0.01)$ (collagen/normDNA) were observed for primed groups in isolation maintained in simulated culture $(186.7 \pm 21.5 \mu \mathrm{g} / \mu \mathrm{g})$ as compared to standard conditions $(110.2 \pm 2.9 \mu \mathrm{g} / \mu \mathrm{g})$ (Fig. $4 \mathrm{~b}$ ). Histological staining for collagen correlated with the biochemical data (Fig. 4c). There was an obvious difference between unprimed and primed groups with limited or no collagen deposition in unprimed BMSC microcapsules [Fig. 4c - (b), (e), (i), (1)] and increased deposition in primed BMSC microcapsules [Fig. 4c-(c), (g), (j), (n)] cultured in isolation and in co-culture with NP.

Immunohistochemistry data revealed that when compared to NP cells co-cultured with unprimed BMSC microcapsules, NP cells cultured in isolation or co-cultured with primed BMSC microcapsules accumulated more collagen II under standard conditions (Fig. 5). Interestingly, NP cells did not deposit similar levels of collagen II under simulated conditions. Furthermore, the images illustrated an obvious difference between unprimed and primed groups with little to no collagen II deposition in unprimed BMSC microcapsules and increased deposition in primed BMSC microcapsules cultured
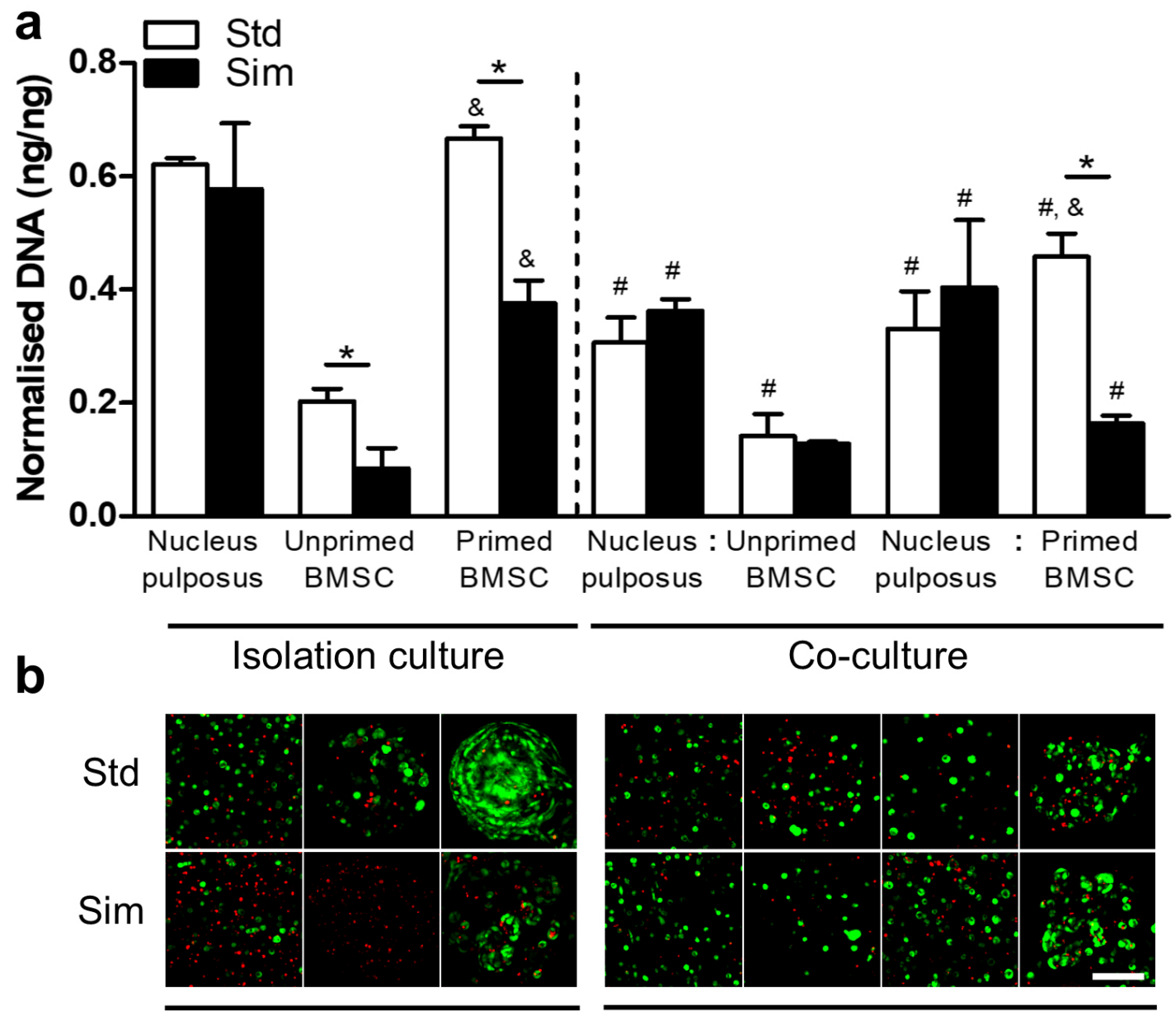

Isolation culture

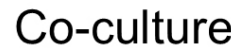

Fig. 2. DNA content and cell viability of in vitro cultures. (a) Total DNA (ng) content (normalised to day 0) at day 28 for NP, unprimed and primed microencapsulated BMSCs in isolation culture and in co-culture under standard (Std) and simulated (Sim) pH media conditions; ${ }^{*}$ significance as compared to isolation culture for same experimental group and media condition, \& significance as compared to unprimed microcapsules for same media condition, ${ }^{*}$ significance as compared to simulated media conditions for same experimental group; $p<0.05 ; n=3$; mean \pm SD represented. (b) Cell viability at day 28; scale bar: $200 \mu \mathrm{m}$. 


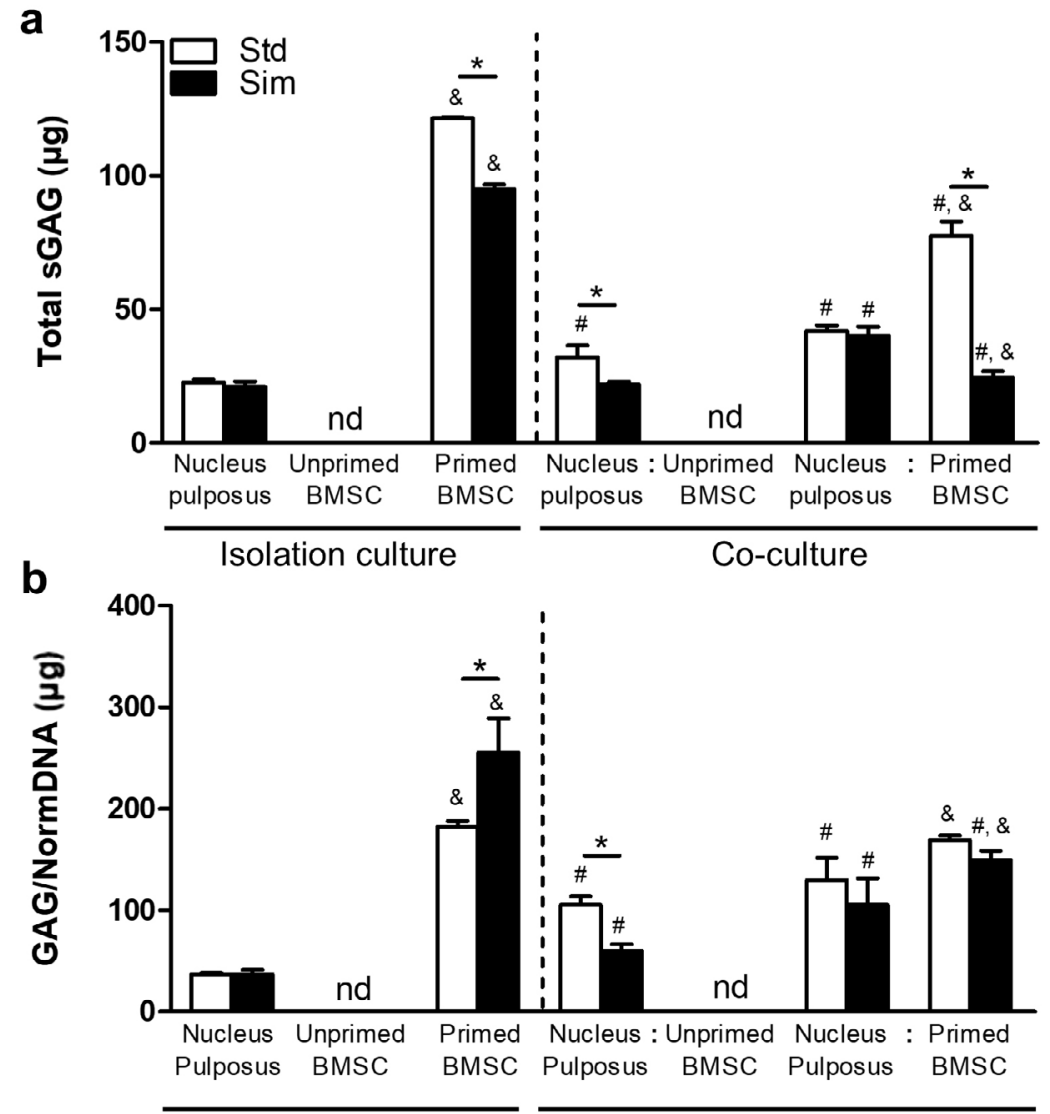

C

Isolation culture

Co-culture

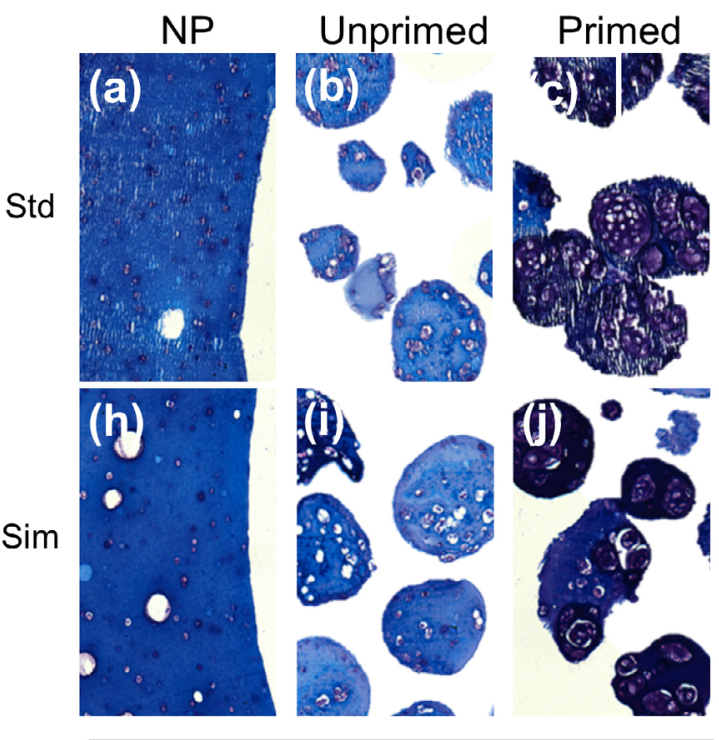

Isolation culture
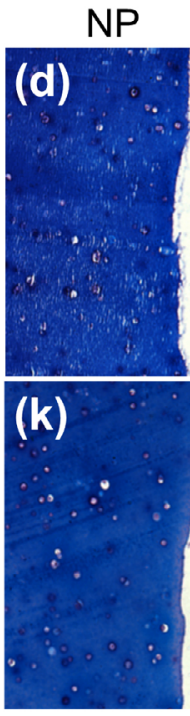
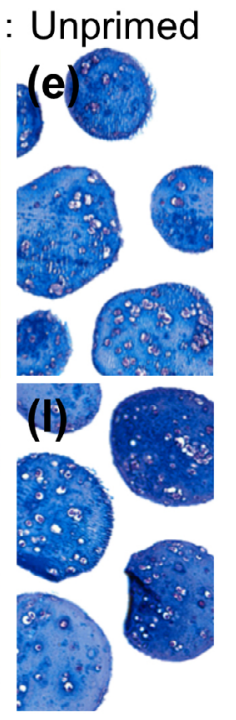

Co-culture
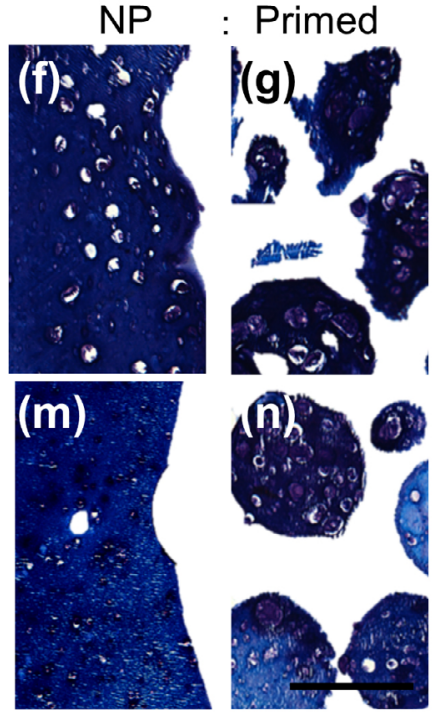
. 

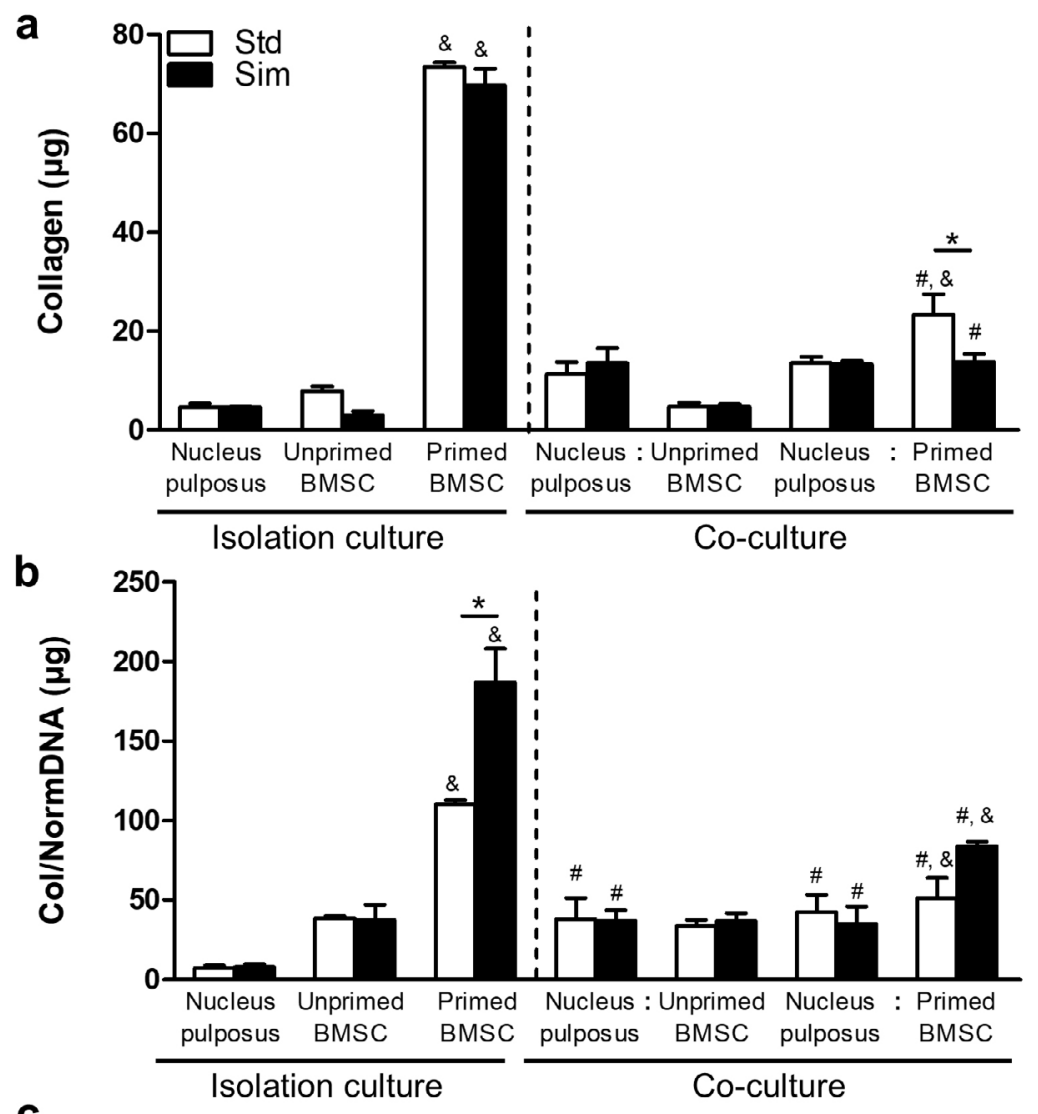

C
NP

(a)
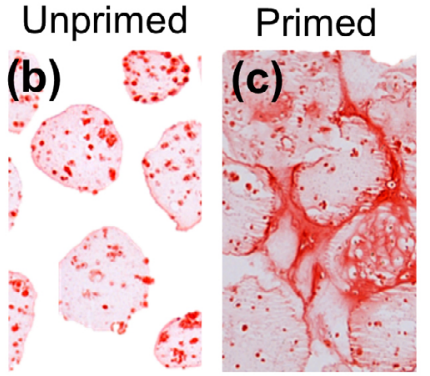

(i)

\section{(h)}

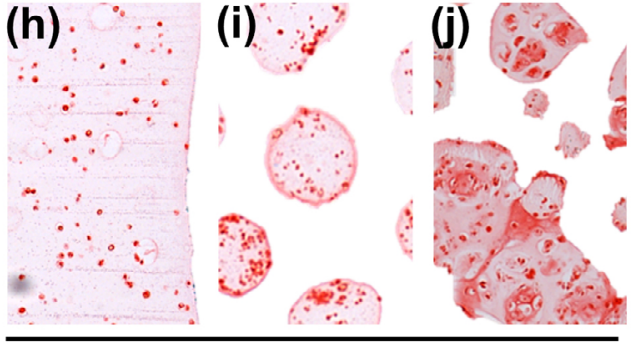

Sim

Isolation culture
NP : Unprimed

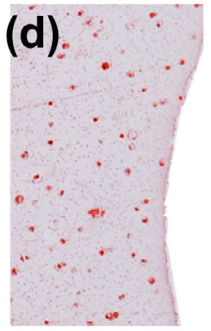

(e)
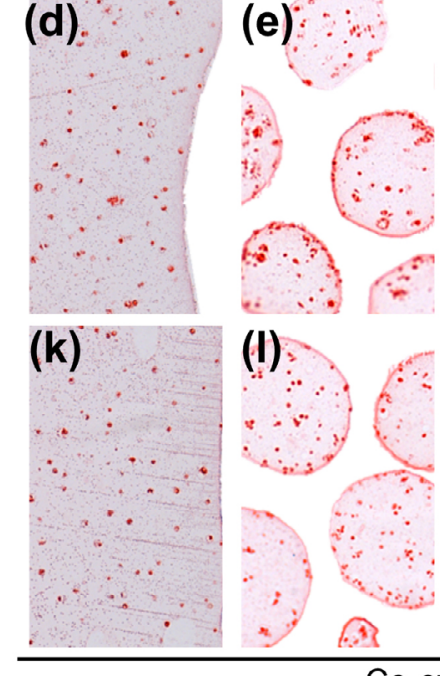

(I)

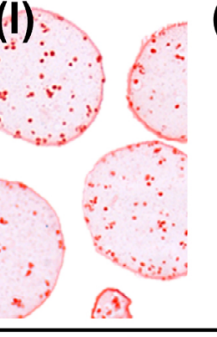

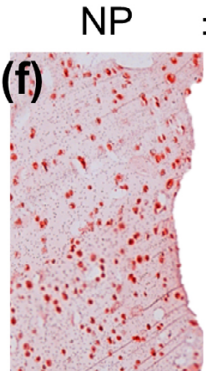

Primed

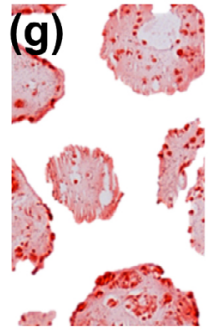

(m)

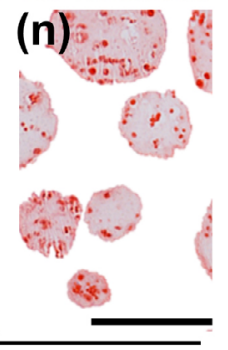

(n)

Co-culture

Fig. 4. Collagen content and deposition of in vitro cultures. (a) Total collagen $(\mu \mathrm{g})$ content normalised to DNA $(\mu \mathrm{g})$ at day 28 for NP, unprimed and primed microencapsulated BMSCs in isolation culture and in co-culture under standard (Std) and simulated (Sim) media conditions. (b) Collagen normalised to DNA $(\mu \mathrm{g} / \mu \mathrm{g})$; collagen content was determined by measuring the hydroxyproline content with a hydroxyproline : collagen ratio of $1: 7.69 .{ }^{*}$ significance as compared to isolation culture for same experimental group and media condition, \& significance as compared to unprimed microcapsules for same media condition, * significance as compared to simulated media conditions for same experimental group; $p<0.05 ; n=3$; mean \pm SD represented. For primed groups, baseline primed (14 d post-priming) were subtracted from day 28 values. (c) Histological evaluation: sections [(a)-(n)] were stained with picrosirius red to identify collagen; scale bar: $200 \mu \mathrm{m}$. 

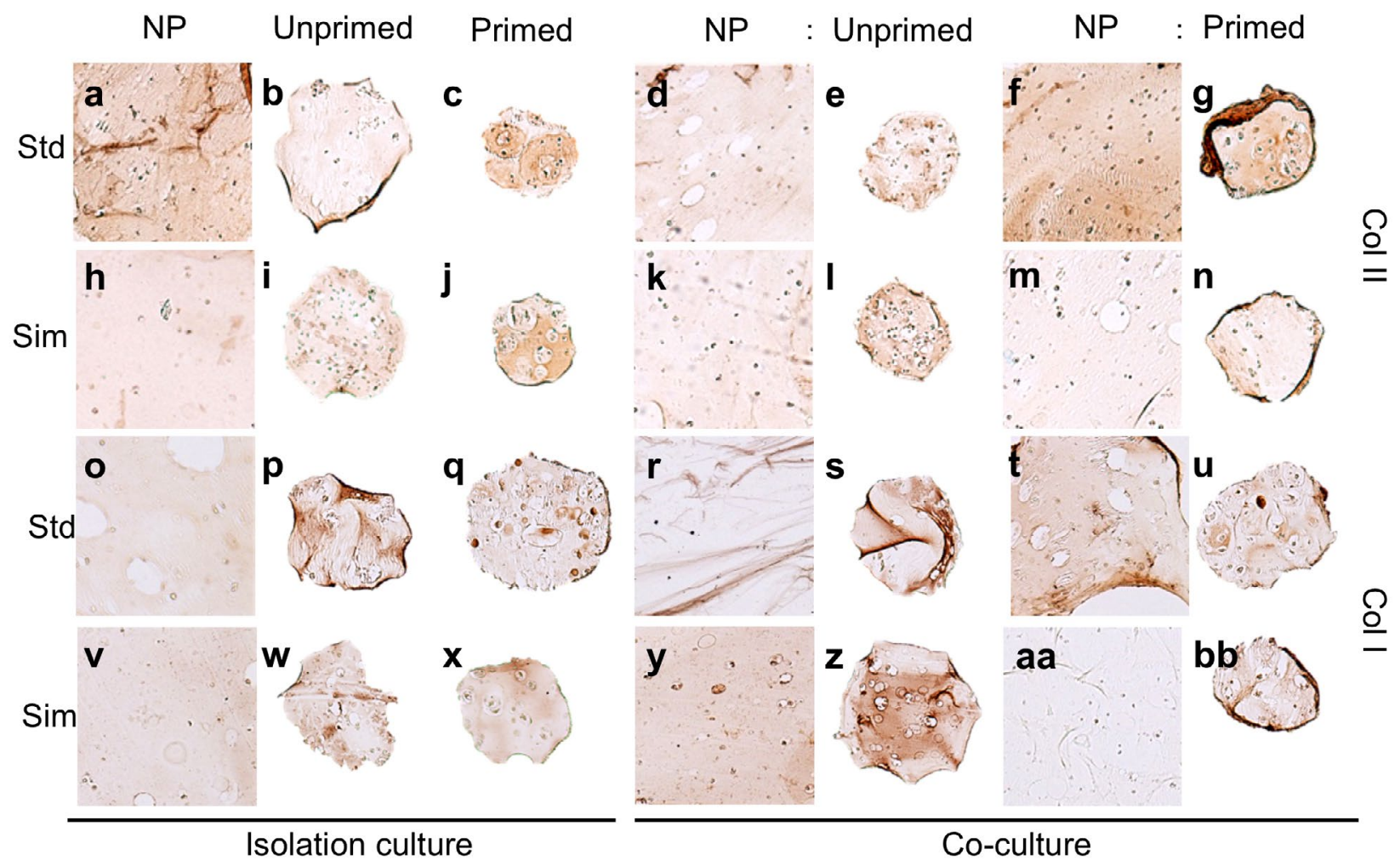

Fig. 5. Collagen type deposition of in vitro cultures. Immunohistochemistry for (a-n) collagen type II and (o-bb) collagen type I at day 28 for NP, unprimed and primed microencapsulated BMSCs in isolation culture and in co-culture under standard (Std) and simulated (Sim) media conditions; scale bar: $100 \mu \mathrm{m}$.

in isolation and in co-culture with the NP. An opposite result was obtained for collagen $\mathrm{I}$, such that unprimed BMSC microcapsules deposited more collagen I as compared to primed BMSC microcapsules in isolation and in co-culture. This was more evident for unprimed BMSC microcapsules co-cultured with NP under simulated conditions.

Ex vivo model - both unprimed and primed BMSC microcapsules demonstrated filling of the cavity defect

Macroscopic images of bovine discs after $28 \mathrm{~d}$ of culture demonstrated a clear difference between empty and healthy control discs with the empty untreated discs exhibiting little to no defect cavity filling in the central region of the IVD and the healthy disc showing a gelatinous mass of NP tissue (Fig. 6a,b). IVDs treated with unprimed and primed microcapsules showed a visibly apparent degree of cavity-filling and regeneration in the central NP region, with the primed group showing a protruding mass comparable to the healthy control (Fig. 6c,d).

Both unprimed and primed BMSC microcapsules accumulate abundant amounts of sGAG and collagen in ex vivo organ culture

Unprimed and primed groups exhibited similar levels of both sGAG and collagen, comparable to the healthy control; the empty control presented an empty hole (the defect appeared to be small but was possibly an artefact due to the embedding procedure) (Fig. 6e-h,m-p). Biochemical data correlated with this observation, such that both unprimed and primed groups exhibited levels of both total sGAG and total collagen comparable to the healthy control. However, when normalised to DNA, collagen data revealed that the unprimed group showed increased content as compared to healthy control and primed groups. Magnified images of the central NP region showed the presence of microcapsules integrated into the surrounding tissue (Fig. 6k, $\mathbf{l}, \mathbf{s}, \mathbf{t}$ ). Live/dead staining showed viable cells after $28 \mathrm{~d}$ of culture in healthy, primed and unprimed discs (Fig. 6u-w).

Biochemical analysis was performed on the NP only and due to the limited amount of the NP tissue in the empty nucleotomy control, it was excluded from the analyses. At day 28, significantly $(p<0.01)$ higher levels of DNA were observed in the primed treatment group $(14013.1 \pm 528.5 \mathrm{ng})$ as compared to both healthy $(5746.7 \pm 1273.3 \mathrm{ng})$ and unprimed $(4460.7 \pm 480.2 \mathrm{ng})$ groups (Fig. 7a). However, there was a significant decrease in DNA content from day 0 , with a $92.53 \%$ decrease in the unprimed group $(81840.9 \pm 8565.4 \mathrm{ng}$ at day 0$)$ and a $57.08 \%$ decrease in the primed group $(51822.2 \pm 2182.1 \mathrm{ng}$ at day 0$)$. With respect to matrix content, all groups demonstrated comparable amounts of sGAG at day 28 (Fig. $7 \mathbf{b}, \mathbf{c})$. This was also observed for collagen, with the 
exception of the unprimed group $(1154.4 \pm 111.5 \mu \mathrm{g} /$ $\mu \mathrm{g})$, which resulted in significantly $(p<0.01)$ more collagen normalised to DNA as compared to the healthy control $(633 \pm 283.3 \mu \mathrm{g} / \mu \mathrm{g})$ and the primed $(364.9 \pm 93.1 \mu \mathrm{g} / \mu \mathrm{g})$ groups (Fig. $7 \mathbf{d}, \mathbf{e})$. Of note, there was a significant $(p<0.01)$ decrease in sGAG and GAG/DNA in the healthy control from day 0 (4367 $\pm 1046.1 \mu \mathrm{g}$ and $1524 \pm 322.9 \mu \mathrm{g} / \mu \mathrm{g}$, respectively) to day $28(1314.7 \pm 452.6 \mu \mathrm{g}$ and $293.88 \pm 83.1 \mu \mathrm{g} / \mu \mathrm{g}$, respectively) (Fig. 7 b,c).

\section{Discussion}

Cryopreservation of injectable microencapsulated BMSCs primed towards a discogenic phenotype prior to transplantation may offer a viable cellular therapeutic approach for IVD regeneration. It potentially eliminates the need for in vivo administration of exogenous growth factors, otherwise required to promote matrix synthesis, in addition to providing 'off-the-shelf' availability. a

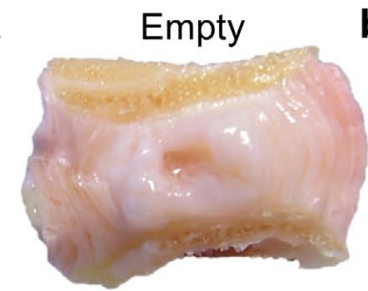

e

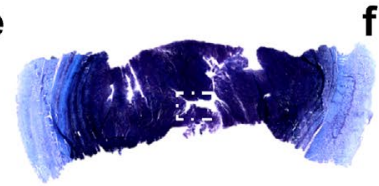

i

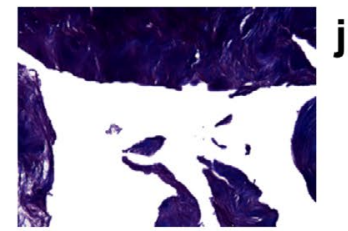

m

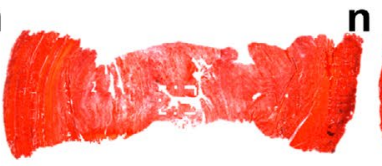

$\mathbf{q}$

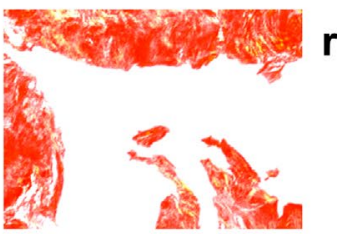

b

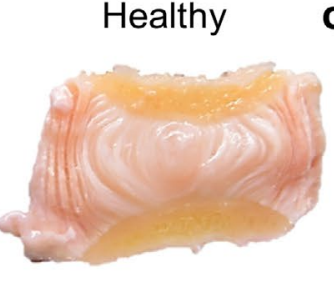

f
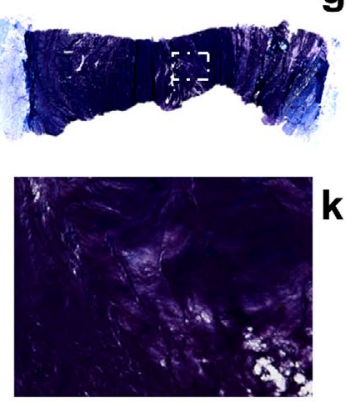

n

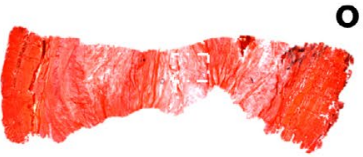

g

o c
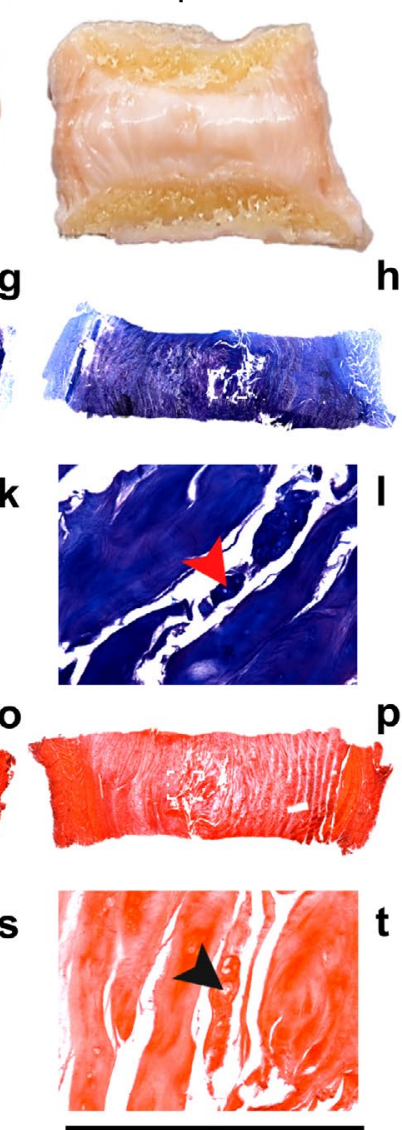

$\mathbf{u}$
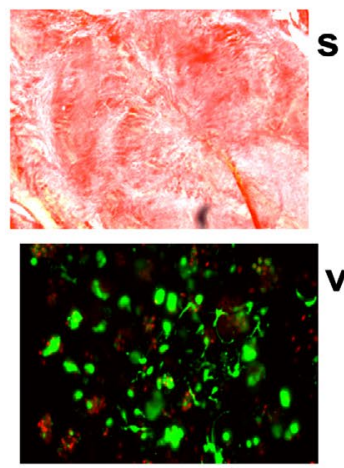

$\mathbf{x}$

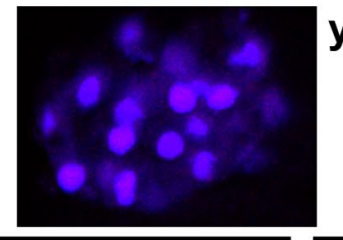

Control
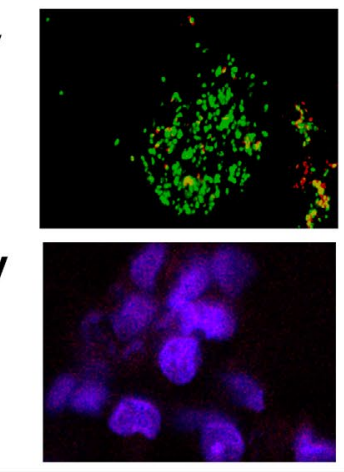

d Primed

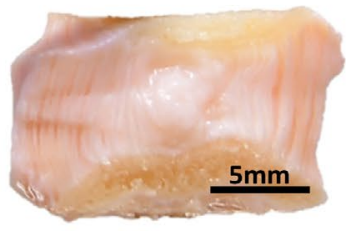

h
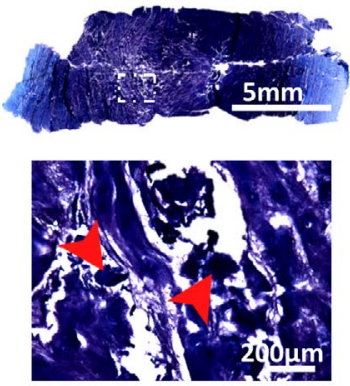

$\stackrel{0}{\circ}$

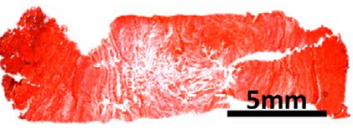

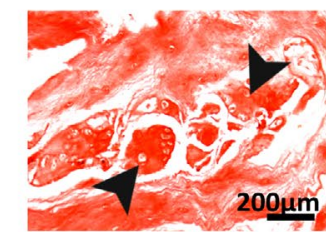

으

w
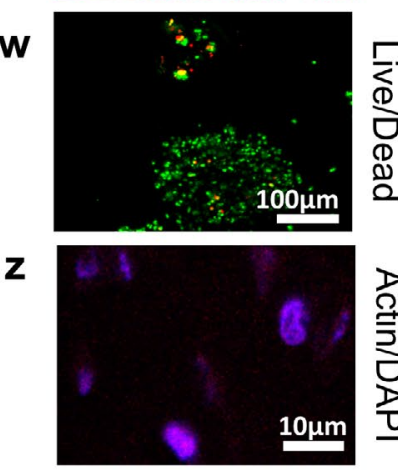

D
$\stackrel{\rho}{\Xi}$
Dे
D
D

Fig. 6. Macroscopic and histological evaluation of ex vivo cultures. (a-d) Macroscopic images of empty, healthy, unprimed and primed microencapsulated BMSC-treated bovine discs after $28 \mathrm{~d}$ of whole organ culture. Scale bar: $5 \mathrm{~mm}$. Histological evaluation: (e-1) sections were stained with aldehyde fuchsin and alcian blue to identify sGAG, deep purple staining indicates GAG accumulation; $(\mathbf{m}-\mathbf{t})$ sections were stained with picrosirius red to identify collagen; (e-h,m-p) lower magnification scale bar: 5 mm; (i-1,q-t) higher magnification scale bar: $200 \mu \mathrm{m}$; arrow heads indicate microcapsules. (u-w) Cell viability at day 28; scale bar: $100 \mu \mathrm{m} .(\mathbf{x}-\mathbf{z})$ Actin/DAPI staining at day 28; scale bar: $10 \mu \mathrm{m}$. 
In vitro co-culture is a method to reproduce in vivo interactions whereby two or more cell types are cultured together, to recapitulate or mimic the typical cellular interactions that occur in vivo. In these systems, cells can communicate with each other through two mechanisms: direct and indirect interactions (Im, 2014). During direct co-culture, separation of the individual cell populations after in vitro culture is challenging. In contrast, this study employed an indirect in vitro co-culture method that allowed physically distinct locations for both BMSCs and NP cells making it possible to ascertain the individual changes to each cell type. Also, the chosen culture condition (i.e. direct or indirect) can have a significant impact on MSC response (Richardson et al., 2006; Scuteri et al., 2014). In particular, direct co-culture stimulated MSC differentiation while indirect co-culture stimulated the release of trophic factors. This may explain the reduced sGAG and collagen accumulation in BMSC microcapsules co-cultured with NP cells as compared to those cultured in isolation, since the BMSCs might be adopting a trophic role in this configuration. BMSCs act as supporting cells under indirect co-culture conditions (i.e. cells do not have cell-cell contact when encapsulated in a hydrogel), which promote NP cell proliferation and matrix synthesis (Naqvi and Buckley, 2015a). This is in line with the work a

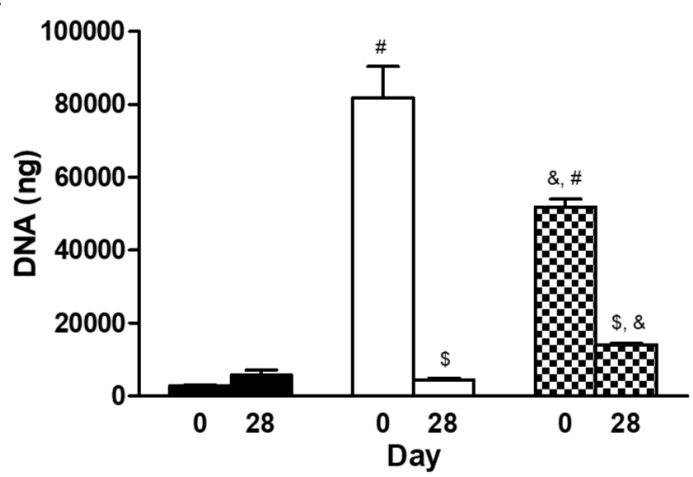

b
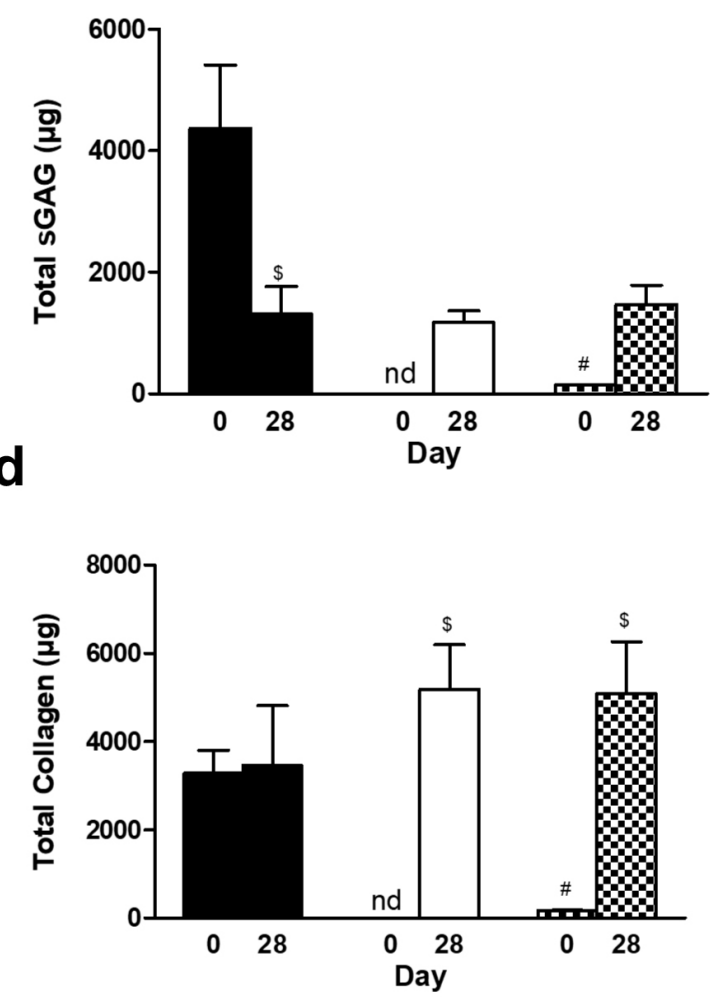

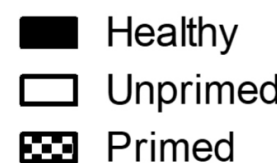

C
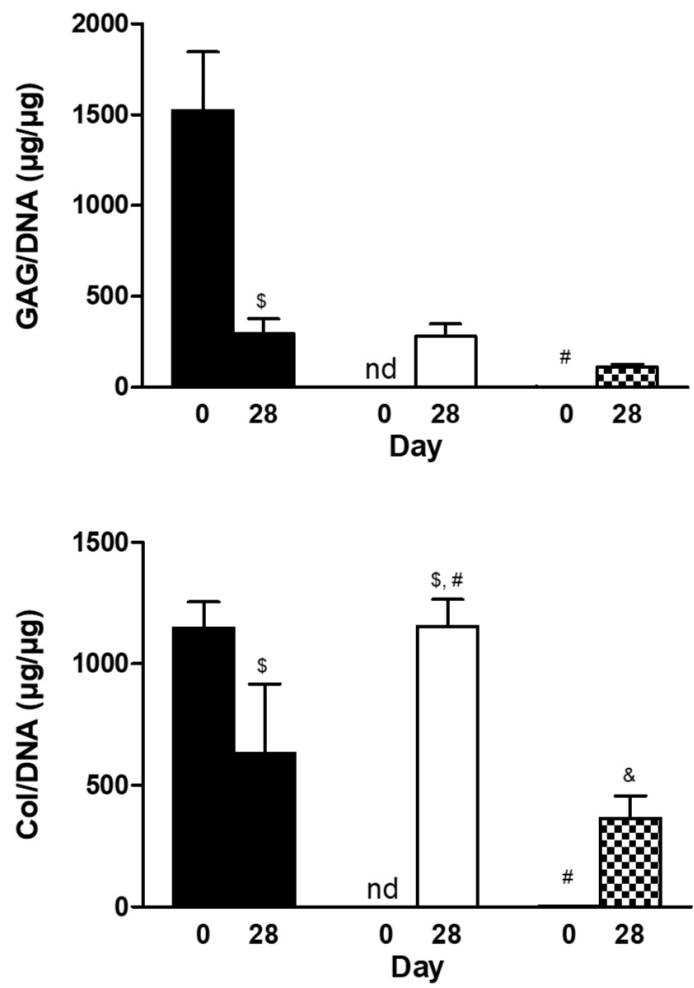

Fig. 7. Biochemical contents of $e x$ vivo cultures. (a) Total DNA (ng) content at day 0 and day 28 for healthy, unprimed and primed microencapsulated BMSC-treated bovine discs. (b) Total sGAG ( $\mu \mathrm{g})$ content. (c) sGAG normalised to DNA ( $\mu \mathrm{g} / \mu \mathrm{g})$. (d) Total collagen $(\mu \mathrm{g})$ content. (e) Collagen normalised to DNA $(\mu \mathrm{g} / \mu \mathrm{g})$; total amount of ECM components was quantified directly from a $5 \mathrm{~mm}$ biopsy used for analysis. " significance as compared to healthy bovine disc for same time point, \& significance as compared to unprimed microcapsule-treated bovine discs for same time point, $\$$ significance as compared to day 0; $p<0.05 ; n=3$; mean $\pm \mathrm{SD}$ represented. 
by Richardson et al. (2006), which shows that MSCs differentiate towards NP-like cells under direct co-culture conditions whereas indirect co-culture conditions (by means of a semipermeable membrane) do not promote MSC differentiation.

NP cell co-culture resulted in significantly more sGAG and collagen as compared to isolation culture, irrespective of BMSC differentiation state. Immunohistochemistry data demonstrated synthesis and deposition of collagen type II. This was particularly important for collagen, since it confirmed that the tissue formed was not merely undesired type I collagen. In addition, this result was in line with a previous study by Nui et al. (2009), whereby co-cultures of NP cells and BMSCs exhibits higher cell growth rate as compared to NP cells cultured in isolation. Furthermore, the mRNA expression levels of collagen II and aggrecan were elevated in co-cultured cells. It is hypothesised that this upregulation is a response to BMSCs releasing trophic factors, i.e. MSCs have a trophic effect on NP cells under indirect co-culture conditions (Strassburg et al., 2010). In another study, Gaetani et al. (2008) demonstrate improved quality of extracellular matrix when NP cells are co-cultured with adiposederived stem cells in an alginate hydrogel system. Of note, these studies investigate MSCs in their undifferentiated state. Undifferentiated MSCs secrete various cytokines and growth factors that are important for tissue repair (Caplan and Dennis, 2006). MSC-secreted bioactive molecules have trophic effects on cells in close proximity, influencing the regeneration of cells or tissue. Recent studies show that one of the trophic factors released by MSCs is the fibroblast growth factor-1 (FGF-1), which leads to increased proliferation of co-cultured chondrocytes (Wu et al., 2013). Other factors identified in the supernatant of MSC-chondrocyte co-cultures include TGF- $\beta 1$, insulin-like growth factor 1 (IGF-1) and bone morphogenetic protein 2 (BMP-2) (Liu et al., 2010), which are regulatory factors important for cell proliferation (Richter, 2009; Shu et al., 2011). Interestingly, the positive effect of co-culture was not limited to those co-cultured with unprimed microcapsules. NP cells accumulated higher levels of sGAG and collagen in the presence of primed microcapsules as well. Based on the findings of the present study, primed microcapsules might play a dual role and exert a trophic effect on NP cells, in addition to possessing the ability to produce matrix. Importantly, in the presence of primed BMSC microcapsules, NP cells were not the only cell type to accumulate matrix components. Primed microcapsules also accumulated sGAG and collagen, suggesting bi-directional signalling of the two cell populations. As a result, primed microcapsules synthesised larger amounts of ECM components as compared to unprimed microcapsules, illustrating the benefit of priming in stromal cell-based regeneration of the IVD. In this scenario, BMSCs can synthesise the appropriate NP-like matrix and cells that may not have fully differentiated can exert a trophic effect on NP cells to synthesise matrix.

Primed BMSC microcapsules resulted in reduced DNA, total sGAG and total collagen in simulated ( $\mathrm{pH}$ 6.8) as compared to standard ( $\mathrm{pH} \mathrm{7.4)} \mathrm{conditions}$ irrespective of whether they were cultured in isolation or in co-culture with NP cells. This is in agreement with a previous study, where BMSCs demonstrate reduced proliferation and accumulate less sGAG and collagen in $\mathrm{pH} 6.8$ conditions as compared with pH 7.4 when cultured under low oxygen conditions (Naqvi and Buckley, 2016). Combining low pH with low glucose results in reduced cell proliferation and sGAG/collagen expression, highlighting the importance of including other microenvironmental factors, such as matrix acidity, in culture systems (Wuertz et al., 2009; Wuertz et al., 2008). Bovine and human GAG synthesis rates are also particularly sensitive to extracellular $\mathrm{pH}$ levels, with the maximum rate occurring between $\mathrm{pH} 6.9$ and $\mathrm{pH} 7.2$ (Ohshima and Urban, 1992). A recent study by Gilbert et al. (2016) demonstrates the importance of acidsensing ion channel (ASICs) and catabolic human $\mathrm{NP}$ cell response to low $\mathrm{pH}$. Acidic $\mathrm{pH}$ can induce cell death as well as upregulation and secretion of pro-inflammatory cytokines and neurogenic factors (Gilbert et al., 2016). Interestingly, NP cells co-cultured with unprimed microcapsules resulted in reduced sGAG and collagen under simulated as compared to standard conditions. NP cells regulate intracellular $\mathrm{pH}$ by expression of molecules such as carbonic anhydrases 9 and 12 (Minogue et al., 2010). However, preliminary data by Richardson et al. (2013) suggest that the expression of these molecules decreases with degeneration and that cells may be unable to sustain the acidic matrix environment over a prolonged time. It is important to note that when sGAG and collagen were normalised to DNA, primed BMSC microcapsules under simulated conditions led to a significantly higher production in isolation culture but not in co-culture with NP.

A promising and perhaps more advanced approach to an in vitro co-culture model that provides a better in vivo-like microenvironment is the use of whole organs, which represent an ex vivo model of the organ of study by maintaining the original architecture and the cell types present (Gantenbein et al., 2006). The nutrient transport of bovine IVDs is similar to that of human IVDs and they are comparable in size (Alini et al., 2008). Nutritional and transport limitations in these large IVDs contribute to the uniquely challenging disc cell microenvironment and present an enormous challenge for clinical translation of cell-based therapies. The results from the present study demonstrated the use of cryopreserved microcapsules in an ex vivo whole organ culture model system such that both unprimed and primed microcapsules accumulated abundant amounts of sGAG and collagen. This is in contrast with the in vitro study results showing unprimed microcapsules to be ineffective at synthesising matrix components (sGAG 
and collagen) but is in agreement with Le Maitre et al. (2009), who have demonstrated the ability of MSCs to differentiate spontaneously upon injection into NP tissue. As such, MSCs may not require continuous exogenous stimulation to induce differentiation and matrix deposition if there are sufficient factors or signals already present in the local microenvironment (Hiyama et al., 2008; Sakai et al., 2005; Zhang et al., 2005). The presence of growth factors such as TGF- $\beta$ (which can promote MSC differentiation towards a discogenic phenotype) (Risbud et al., 2004; Steck et al., 2005) sequestered in the IVD matrix may be sufficient to direct MSC differentiation. However, the IVD tissue microenvironment is composed of native cells and ECM in addition to growth factors, all of which may play a role in the differentiation of the MSCs post injection. A possible limitation of the present study is the lack of a cell-only control. However, cells only without a carrier system come with several established challenges, some of which include cell leakage during injection, cell death due to shear forces and host immune response (Murua et al., 2008; Richardson et al., 2008). In contrast, cells combined with a carrier system have many advantages and some of the challenges associated with the use of cells only are avoided: less cell leakage, less cell death, immune privileged environment (Murua et al., 2008; Richardson et al., 2008). In particular, EHDA provides a one-step technique for fast cell encapsulation, with no in situ gelling necessary and and allows cells to be manipulated within the carrier prior to injection (Bartolovic et al., 2010; Jayasinghe, 2007; Jayasinghe, 2011; Jayasinghe et al., 2006; Naqvi et al., 2016; Workman et al., 2014).

The ex vivo results of the present study emphasised the importance of employing a relevant model system when investigating therapeutic strategies for NP regeneration. Importantly, the study employed the use of bovine caudal discs, which are similar in size to the human lumbar disc (Alini et al., 2008). The NP of bovine IVDs is white and fibrous in appearance, similar to human disc tissue and substantially different from the gelatinous NP of porcine and rodent discs (Urban and Roberts, 2003). Furthermore, should the ex vivo model demonstrate failure of the proposed therapy, it obviates the need for in vivo tests, thereby reducing the need for animal models. However, establishing clinically relevant models of disc degeneration is pivotal for translation. Different strategies have been developed to induce disc degeneration. The present study employed a surgical model of disc degeneration by performing a nucleotomy. Although there were inherent limitations with its use, the access route to the NP region induced mechanical damage to the IVD by creating an annular defect. In addition, this model allowed removal of controlled quantities of NP tissue from the disc and it was somewhat similar to the in vitro co-culture model system used.

Regardless of the chosen approach (in vitro or ex vivo), the balance between relevant matrix synthesis and feasibility has to be evaluated carefully. In fact, the development of analyses applicable to advanced in vitro as well as ex vivo models should be considered to gain further understanding. Overall, the in vitro study showed unprimed microcapsules to be inadequate at synthesising matrix components (sGAG and collagen). This was in contrast with the ex vivo whole organ culture model system which demonstrated the use of cryopreserved microcapsules such that both unprimed and primed microcapsules accumulated abundant amounts of sGAG and collagen. This finding is important since it would potentially simplify treatment strategies and lower costs due to reduced manipulation of MSCs prior to transplantation. In conclusion, cryopreservation of BMSC microcapsules (primed or unprimed) may offer a feasible strategy for predesigned delivery through cryobanking for on-demand regeneration of the IVD.

\section{Acknowledgements}

SMN was supported by the Graduate Research Education Programme in Engineering (GREP-Eng), PRTLI Cycle 5 funded programme. PRTLI is $50 \%$ cofunded under the European Regional Development Fund. JG and CTB were supported by Science Foundation Ireland Career Development Award (15/ CDA/3476).

\section{References}

Aguiar DJ, Johnson SL, Oegema TR (1999) Notochordal cells interact with nucleus pulposus cells: regulation of proteoglycan synthesis. Exp Cell Res 246: 129-137.

Alini M, Eisenstein SM, Ito K, Little C, Kettler AA, Masuda K, Melrose J, Ralphs J, Stokes I, Wilke HJ (2008) Are animal models useful for studying human disc disorders/degeneration? Eur Spine J 17: 2-19.

Bartels EM, Fairbank JC, Winlove CP, Urban JP (1998) Oxygen and lactate concentrations measured in vivo in the intervertebral discs of patients with scoliosis and back pain. Spine (Phila Pa 1976) 23: 1-8.

Bartolovic K, Mongkoldhumrongkul N, Waddington SN, Jayasinghe SN, Howe SJ (2010) The differentiation and engraftment potential of mouse hematopoietic stem cells is maintained after bio-electrospray. Analyst 135: 157-164.

Bucher C, Gazdhar A, Benneker LM, Geiser T, Gantenbein-Ritter B (2013) Nonviral gene delivery of growth and differentiation factor 5 to human mesenchymal stem cells injected into a 3D bovine intervertebral disc organ culture system. Stem Cells Int 2013: 326828. DOI: 10.1155/2013/326828.

Buckwalter JA (1995) Aging and degeneration of the human intervertebral disc. Spine (Phila Pa 1976) 20: 1307-1314. 
Caplan AI, Dennis JE (2006) Mesenchymal stem cells as trophic mediators. J Cell Biochem 98: 10761084.

Chan SC, Gantenbein-Ritter B, Leung VY, Chan D, Cheung KM, Ito K (2010) Cryopreserved intervertebral disc with injected bone marrowderived stromal cells: a feasibility study using organ culture. Spine J 10: 486-496.

Chan SC, Walser J, Kappeli P, Shamsollahi MJ, Ferguson SJ, Gantenbein-Ritter B (2013) Region specific response of intervertebral disc cells to complex dynamic loading: an organ culture study using a dynamic torsion-compression bioreactor. PLoS One 8: e72489. DOI: 10.1371/journal.pone.0072489.

Diamant B, Karlsson J, Nachemson A (1968) Correlation between lactate levels and $\mathrm{pH}$ in discs of patients with lumbar rhizopathies. Experientia 24: 1195-1196.

Errington RJ, Puustjarvi K, White IR, Roberts S, Urban JP (1998) Characterisation of cytoplasm-filled processes in cells of the intervertebral disc. J Anat 192 (Pt 3): 369-378.

Furtwangler T, Chan SC, Bahrenberg G, Richards PJ, Gantenbein-Ritter B (2013) Assessment of the matrix degenerative effects of MMP-3, ADAMTS-4, and HTRA1, injected into a bovine intervertebral disc organ culture model. Spine (Phila Pa 1976) 38: E1377-1387.

Gaetani P, Torre ML, Klinger M, Faustini M, Crovato F, Bucco M, Marazzi M, Chlapanidas T, Levi D, Tancioni F, Vigo D, Rodriguez y Baena R (2008) Adipose-derived stem cell therapy for intervertebral disc regeneration: an in vitro reconstructed tissue in alginate capsules. Tissue Eng Part A 14: 1415-1423.

Gahunia HK, Vieth R, Pritzker K (2002) Novel fluorescent compound (DDP) in calf, rabbit, and human articular cartilage and synovial fluid. J Rheumatol 29: 154-160.

Gantenbein B, Grunhagen T, Lee CR, van Donkelaar CC, Alini M, Ito K (2006) An in vitro organ culturing system for intervertebral disc explants with vertebral endplates: a feasibility study with ovine caudal discs. Spine (Phila Pa 1976) 31: 2665-2673.

Gasperini L, Maniglio D, Migliaresi C (2013) Microencapsulation of cells in alginate through an electrohydrodynamic process. J Bioact Compat Polym 28: 413-425.

Gilbert HT, Hodson N, Baird P, Richardson SM, Hoyland JA (2016) Acidic $\mathrm{pH}$ promotes intervertebral disc degeneration: acid-sensing ion channel -3 as a potential therapeutic target. Sci Rep 6: 37360 . DOI: 10.1038/srep37360.

Hiyama A, Mochida J, Iwashina T, Omi H, Watanabe T, Serigano K, Tamura F, Sakai D (2008) Transplantation of mesenchymal stem cells in a canine disc degeneration model. J Orthop Res 26: 589-600.

Horner HA, Roberts S, Bielby RC, Menage J, Evans H, Urban JP (2002) Cells from different regions of the intervertebral disc: effect of culture system on matrix expression and cell phenotype. Spine (Phila Pa 1976) 27: 1018-1028.

Horner HA, Urban JP (2001) 2001 Volvo Award Winner in basic science studies: Effect of nutrient supply on the viability of cells from the nucleus pulposus of the intervertebral disc. Spine (Phila Pa 1976) 26: 2543-2549.

Ignat'eva NY, Danilov NA, Averkiev SV, Obrezkova MV, Lunin VV, Sobol EN (2007) Determination of hydroxyproline in tissues and the evaluation of the collagen content of the tissues. J Anal Chem 62: 51-57.

Im GI (2014) Coculture in musculoskeletal tissue regeneration. Tissue Eng Part B Rev 20: 545-554.

Ishihara H, McNally DS, Urban JP, Hall AC (1996) Effects of hydrostatic pressure on matrix synthesis in different regions of the intervertebral disk. J Appl Physiol (1985) 80: 839-846.

Ishihara H, Warensjo K, Roberts S, Urban JP (1997) Proteoglycan synthesis in the intervertebral disk nucleus: the role of extracellular osmolality. Am J Physiol 272: C1499-1506.

Jayasinghe SN (2007) Submerged electrosprays: a versatile approach for microencapsulation. J Microencapsul 24: 430-444.

Jayasinghe SN (2011) Bio-electrosprays: from bio-analytics to a generic tool for the health sciences. Analyst 136: 878-890.

Jayasinghe SN, Qureshi AN, Eagles PA (2006) Electrohydrodynamic jet processing: an advanced electric-field-driven jetting phenomenon for processing living cells. Small 2: 216-219.

Kafienah W, Sims TJ (2004) Biochemical methods for the analysis of tissue-engineered cartilage. Methods Mol Biol 238: 217-230.

Katz MM, Hargens AR, Garfin SR (1986) Intervertebral disc nutrition. Diffusion versus convection. Clin Orthop Relat Res: 243-245.

Keshari KR, Lotz JC, Link TM, Hu S, Majumdar S, Kurhanewicz J (2008) Lactic acid and proteoglycans as metabolic markers for discogenic back pain. Spine (Phila Pa 1976) 33: 312-317.

Le Maitre CL, Baird P, Freemont AJ, Hoyland JA (2009) An in vitro study investigating the survival and phenotype of mesenchymal stem cells following injection into nucleus pulposus tissue. Arthritis Res Ther 11: R20. DOI: 10.1186/ar2611.

Le Visage C, Kim SW, Tateno K, Sieber AN, Kostuik JP, Leong KW (2006) Interaction of human mesenchymal stem cells with disc cells: changes in extracellular matrix biosynthesis. Spine (Phila Pa 1976) 31: 2036-2042.

Liu X, Sun H, Yan D, Zhang L, Lv X, Liu T, Zhang W, Liu W, Cao Y, Zhou G (2010) In vivo ectopic chondrogenesis of BMSCs directed by mature chondrocytes. Biomaterials 31: 9406-9414.

Minogue BM, Richardson SM, Zeef LA, Freemont AJ, Hoyland JA (2010) Characterization of the human nucleus pulposus cell phenotype and evaluation of novel marker gene expression to define adult stem cell differentiation. Arthritis Rheum 62: 3695-3705. 
Murua A, Portero A, Orive G, Hernandez RM, de Castro M, Pedraz JL (2008) Cell microencapsulation technology: towards clinical application. J Control Release 132: 76-83.

Naqvi SM, Buckley CT (2015a) Differential response of encapsulated nucleus pulposus and bone marrow stem cells in isolation and coculture in alginate and chitosan hydrogels. Tissue Eng Part A 21: 288-299.

Naqvi SM, Buckley CT (2015b) Extracellular matrix production by nucleus pulposus and bone marrow stem cells in response to altered oxygen and glucose microenvironments. J Anat 227: 757-766.

Naqvi SM, Buckley CT (2016) Bone marrow stem cells in response to intervertebral disc-like matrix acidity and oxygen concentration: implications for cell-based regenerative therapy. Spine (Phila Pa 1976) 41: 743-750.

Naqvi SM, Gansau J, Buckley CT (2018) Priming and cryopreservation of microencapsulated marrow stromal cells as a strategy for intervertebral disc regeneration. Biomed Mater 13: 034106. DOI: 10.1088/1748-605X/aaab7f.

Naqvi SM, Vedicherla S, Gansau J, McIntyre T, Doherty M, Buckley CT (2016) Living cell factories electrosprayed microcapsules and microcarriers for minimally invasive delivery. Advd Mater 28: 56625671.

Nerlich AG, Schleicher ED, Boos N (1997) 1997 Volvo Award winner in basic science studies. Immunohistologic markers for age-related changes of human lumbar intervertebral discs. Spine (Phila Pa 1976) 22: 2781-2795.

Niu CC, Yuan LJ, Lin SS, Chen LH, Chen WJ (2009) Mesenchymal stem cell and nucleus pulposus cell coculture modulates cell profile. Clin Orthop Relat Res 467: 3263-3272.

Oegema TR Jr, Johnson SL, Aguiar DJ, Ogilvie JW (2000) Fibronectin and its fragments increase with degeneration in the human intervertebral disc. Spine (Phila Pa 1976) 25: 2742-2747.

Ohshima H, Urban JP (1992) The effect of lactate and $\mathrm{pH}$ on proteoglycan and protein synthesis rates in the intervertebral disc. Spine (Phila Pa 1976) 17: 1079-1082.

Ohshima H, Urban JP, Bergel DH (1995) Effect of static load on matrix synthesis rates in the intervertebral disc measured in vitro by a new perfusion technique. J Orthop Res 13: 22-29.

Oloyede A, Broom ND, Martinez JB (1998) Experimental factors governing the internal stress state of the intervertebral disc. Med Eng Phys 20: 631-637.

Oshima H, Ishihara H, Urban JP, Tsuji H (1993) The use of coccygeal discs to study intervertebral disc metabolism. J Orthop Res 11: 332-338.

Race A, Broom ND, Robertson P (2000) Effect of loading rate and hydration on the mechanical properties of the disc. Spine (Phila Pa 1976) 25: 662669.
Rajasekaran S, Vidyadhara S, Subbiah M, Kamath V, Karunanithi R, Shetty AP, Venkateswaran K, Babu M, Meenakshi J (2010) ISSLS prize winner: a study of effects of in vivo mechanical forces on human lumbar discs with scoliotic disc as a biological model: results from serial postcontrast diffusion studies, histopathology and biochemical analysis of twentyone human lumbar scoliotic discs. Spine (Phila Pa 1976) 35: 1930-1943.

Razaq S, Urban JP, Wilkins RJ (2000) Regulation of intracellular $\mathrm{pH}$ by bovine intervertebral disc cells. Cell Physiol Biochem 10: 109-115.

Richardson SM, Freemont AJ, Hoyland JA (2013) Pathogenesis of intervertebral disc degeneration. In: The intervertebral disc: molecular and structural studies of the disc in health and disease, Shapiro MI, Risbud VM edition, Springer Vienna, Vienna, pp 177200.

Richardson SM, Hughes N, Hunt JA, Freemont AJ, Hoyland JA (2008) Human mesenchymal stem cell differentiation to NP-like cells in chitosanglycerophosphate hydrogels. Biomaterials 29: 85-93.

Richardson SM, Walker RV, Parker S, Rhodes NP, Hunt JA, Freemont AJ, Hoyland JA (2006) Intervertebral disc cell-mediated mesenchymal stem cell differentiation. Stem Cells 24: 707-716.

Richter W (2009) Mesenchymal stem cells and cartilage in situ regeneration. J Intern Med 266: 390405.

Risbud MV, Albert TJ, Guttapalli A, Vresilovic EJ, Hillibrand AS, Vaccaro AR, Shapiro IM (2004) Differentiation of mesenchymal stem cells towards a nucleus pulposus-like phenotype in vitro: implications for cell-based transplantation therapy. Spine (Phila Pa 1976) 29: 2627-2632.

Roberts S, Eisenstein SM, Menage J, Evans EH, Ashton IK (1995) Mechanoreceptors in intervertebral discs. Morphology, distribution, and neuropeptides. Spine (Phila Pa 1976) 20: 2645-2651.

Roberts S, Menage J, Duance V, Wotton S, Ayad S (1991) 1991 Volvo Award in basic sciences. Collagen types around the cells of the intervertebral disc and cartilage end plate: an immunolocalization study. Spine (Phila Pa 1976) 16: 1030-1038.

Sakai D, Mochida J, Iwashina T, Watanabe T, Nakai T, Ando K, Hotta T (2005) Differentiation of mesenchymal stem cells transplanted to a rabbit degenerative disc model: potential and limitations for stem cell therapy in disc regeneration. Spine (Phila Pa 1976) 30: 2379-2387.

Sakai D, Mochida J, Yamamoto Y, Nomura T, Okuma M, Nishimura K, Nakai T, Ando K, Hotta T (2003) Transplantation of mesenchymal stem cells embedded in Atelocollagen gel to the intervertebral disc: a potential therapeutic model for disc degeneration. Biomaterials 24: 3531-3541.

Scuteri A, Donzelli E, Rodriguez-Menendez V, Ravasi M, Monfrini M, Bonandrini B, Figliuzzi M, Remuzzi A, Tredici G (2014) A double mechanism for the mesenchymal stem cells' positive effect on 
pancreatic islets. PLoS One 9: e84309. DOI: 10.1371/ journal.pone.008430.

Shu B, Zhang M, Xie R, Wang M, Jin H, Hou W, Tang D, Harris SE, Mishina Y, O'Keefe RJ, Hilton MJ, Wang Y, Chen D (2011) BMP2, but not BMP4, is crucial for chondrocyte proliferation and maturation during endochondral bone development. J Cell Sci 124: 3428-3440.

Simunic DI, Broom ND, Robertson PA (2001) Biomechanical factors influencing nuclear disruption of the intervertebral disc. Spine (Phila Pa 1976) 26: 1223-1230.

Spillekom S, Smolders LA, Grinwis GC, Arkesteijn IT, Ito K, Meij BP, Tryfonidou MA (2014) Increased osmolarity and cell clustering preserve canine notochordal cell phenotype in culture. Tissue Eng Part C Methods 20: 652-662.

Steck E, Bertram H, Abel R, Chen B, Winter A, Richter W (2005) Induction of intervertebral disc-like cells from adult mesenchymal stem cells. Stem Cells 23: 403-411.

Stoyanov JV, Gantenbein-Ritter B, Bertolo A, Aebli N, Baur M, Alini M, Grad S (2011) Role of hypoxia and growth and differentiation factor -5 on differentiation of human mesenchymal stem cells towards intervertebral nucleus pulposus-like cells. Eur Cell Mater 21: 533-547.

Strassburg S, Richardson SM, Freemont AJ, Hoyland JA (2010) Co-culture induces mesenchymal stem cell differentiation and modulation of the degenerate human nucleus pulposus cell phenotype. Regen Med 5: 701-711.

Urban JP, Holm S, Maroudas A, Nachemson A (1982) Nutrition of the intervertebral disc: effect of fluid flow on solute transport. Clin Orthop Relat Res: 296-302.

Urban JP, Smith S, Fairbank JC (2004) Nutrition of the intervertebral disc. Spine (Phila Pa 1976) 29: 2700-2709.

Urban JPG, Roberts S (2003) Degeneration of the intervertebral disc. Arthritis Res Ther 5: 120-130.

Vadala G, Studer RK, Sowa G, Spiezia F, Iucu C, Denaro V, Gilbertson LG, Kang JD (2008) Coculture of bone marrow mesenchymal stem cells and nucleus pulposus cells modulate gene expression profile without cell fusion. Spine (Phila Pa 1976) 33: 870-876.

Wang L, Rao RR, Stegemann JP (2013) Delivery of mesenchymal stem cells in chitosan/collagen microbeads for orthopedic tissue repair. Cells Tissues Organs 197: 333-343.

Workman VL, Tezera LB, Elkington PT, Jayasinghe SN (2014) Controlled generation of microspheres incorporating extracellular matrix fibrils for threedimensional cell culture. Adv Funct Mater 24: 26482657.

Wu L, Leijten J, van Blitterswijk CA, Karperien M (2013) Fibroblast growth factor-1 is a mesenchymal stromal cell-secreted factor stimulating proliferation of osteoarthritic chondrocytes in co-culture. Stem Cells Dev 22: 2356-2367.
Wuertz K, Godburn K, Iatridis JC (2009) MSC response to $\mathrm{pH}$ levels found in degenerating intervertebral discs. Biochem Biophys Res Commun 379: 824-829.

Wuertz K, Godburn K, Neidlinger-Wilke C, Urban J, Iatridis JC (2008) Behavior of mesenchymal stem cells in the chemical microenvironment of the intervertebral disc. Spine (Phila Pa 1976) 33: 18431849.

Yamamoto Y, Mochida J, Sakai D, Nakai T, Nishimura K, Kawada H, Hotta T (2004) Upregulation of the viability of nucleus pulposus cells by bone marrow-derived stromal cells: significance of direct cell-to-cell contact in coculture system. Spine (Phila Pa 1976) 29: 1508-1514.

Zhang YG, Guo X, Xu P, Kang LL, Li J (2005) Bone mesenchymal stem cells transplanted into rabbit intervertebral discs can increase proteoglycans. Clin Orthop Relat Res: 219-226.

\section{Discussion with Reviewers}

Sebastian Wangler: Why did you choose alginate as a carrier material?

Authors: MSC encapsulation in an alginate hydrogel facilitates a chondrocyte-like rounded morphology, in contrast to other culture systems, such as collagen, which promotes a spread morphology (Bacakova et al., 2004; Dadsetan et al., 2011; Kwon et al., 2010; Liu et al., 2011). In addition, improved NP-like matrix components' production in alginate as compared to chitosan is demonstrated (Naqvi and Buckley, 2015a). This could be due to a change in cell morphology from a round shape in alginate to a spread shape in chitosan, resulting in an altered cell phenotype. This may be due to the charge of the hydrogel in which the cells are encapsulated; alginate is an anionic polymer and does not permit cell adhesion or binding sites, whereas chitosan is a cationic polymer and facilitates adherence of MSCs and development of focal adhesions (Naqvi and Buckley, 2015a). Cell shape and spreading regulate proliferation and differentiation of MSCs (Bacakova et al., 2004; Dadsetan et al., 2011; Kwon et al., 2010; Liu et al., 2011; additional references). In general, a rounded morphology results in chondrocyte-like cells producing larger amounts of sGAG and collagen type II (Mathieu and Loboa, 2012). A spread morphology results in fibroblastlike cells producing less sGAG and higher levels of collagen type I. Interestingly, Dadsetan et al. (2011) have cultured chondrocytes on anionic hydrogels and demonstrate significantly enhanced production of chondrocyte-specific proteins. This is in line with previous results (Naqvi and Buckley, 2015a) whereby alginate, a negatively charged polymer, enhances the production of sGAG and collagen type II.

Stephen Richardson: While cell viability following ex vivo culture was not directly assessed, the DNA 
content (Fig. 7a) suggested a significant decrease in cell number over time, even after priming. Do the authors think this was due to seeding density or could there be further decline if the time course was extended irrespective of total cell number? In an in vivo context, do the authors think the apparent cell death would undermine success of their proposed therapy?

Authors: The cell density coupled with the harsh microenvironment may be playing a significant role. Numerous studies have explored the effects of other IVD-like microenvironmental conditions, such as osmolarity, on MSC survival and differentiation. For example, Weurtz et al. (2008) have shown that culture conditions consisting of low glucose, elevated osmolarity (485mOsm) and matrix acidity ( $\mathrm{pH}$ 6.8) are detrimental for MSCs, resulting in diminished proliferation and protein expression. In addition, it is important to understand and predict how MSCs respond to pro-inflammatory cytokines post implantation into a degenerate IVD microenvironment. For example, MSCs cultured in the presence of IL-1 $\beta$ results in diminished expression of key matrix components and lower functional properties (Felka et al., 2009, additional reference).

Once cryopreserved primed BMSC microcapsules would restore the matrix within the NP, the organ would not be able to provide nutrients for proliferating cells due to the established harsh microenvironment of the IVD. Therefore, some cell death would not be detrimental. As long as there are sufficient cells to maintain the matrix, it may be possible to attain a good outcome. In the worst-case scenario, it may be possible or necessary to provide a second dose after some time to introduce more matrix-forming cells.

Also, based on the in vitro experiments performed, BMSCs induced NP cells to produce matrix. Therefore, the paracrine/trophic effect of encouraging NP cells to deposit matrix is still an important and beneficial consequence of this therapy. Using lower cell densities may not achieve this same beneficial effect.

Stephen Richardson: The study employed porcine NP cells and MSCs within a bovine explant model. Porcine NP retains a large proportion of notochordal cells (Alini et al., 2008) and, while smaller porcine NP cells were separated for use, they might have a different phenotype and response to cells from species where notochordal cells are lost, such as bovine or human. Do the authors think the choice of species influenced the outcomes or whether similar outcomes would be observed with human cells?

Authors: Porcine tissue contains a population of notochordal cells (NC) that have a different phenotype as compared to adult NP cells (Alini et al., 2008). As such, there are known limitations when utilising porcine tissue as a model for NP regeneration. In order to separate these different cell populations, the tissue digest was passed through a $40 \mu \mathrm{m}$ cell strainer. This approach was adopted based on a protocol described previously (Spillekom et al., 2014). Histological evaluation of the freshly isolated NP cells demonstrated that the filtrate mostly contained spindle-shaped cells (a key indicator of NP cells) while NC clusters were collected in the strainer. NP cells exhibit a rounded nucleus while NC cell nuclei appear irregular with most of the volume occupied by vacuoles (Spillekom et al., 2014).

Benjamin Gantenbein: The authors isolated the BMSCs and donor-matched NP cells from porcine femurs and injected the porcine BMSCs primed or unprimed into a bovine IVD model. How can the authors exclude that the NPC (nucleus pulposus cells) group was lacking the presence of NC after filtering? Could the results not be affected by remnant secretome or cross-species factors from the NC? Would it not have been easier to inject the porcine microbeads into porcine organ culture model? Or formulated the other way around, would it not be conceptionally easier to isolate the BMSCs from bovine animals and to inject these into a bovine allogenic environment. In these cases, all the cross-species effects and the hassle to filter out the notochordal cells from the porcine discs would not have been a requirement?

Authors: The author believe the protocol adopted resulted in an acceptable separation of NP and NC cells. As these cells were washed repeatedly and culture-expanded, it is unlikely that there was any remnant NC secretome present. Regarding the cell type injected into the ex vivo model, porcine BMSCs were used to build on previous work performed by the authors allowing to compare results to previous studies. Importantly, for the ex vivo model, no porcine NP cells were introduced into the disc. Nonetheless, it is not possible to deny that there might be crossspecies effects. Changing species would introduce confounding challenges that would require a full set of controls with bovine BMSCs to ensure the results obtained were not due to change in species. It is important to note that harvesting bovine tissue and isolating bone marrow stromal cells is technically challenging given the large size of the joints. Overall, the authors believe, given the similarity of bovine and human discs, that the outcome is still representative as a first path model system.

\section{Additional references}

Bacakova L, Filova E, Rypacek F, Svorcik V, Stary V (2004) Cell adhesion on artificial materials for tissue engineering. Physiol Res 53 Suppl 1: S35-45.

Dadsetan M, Pumberger M, Casper ME, Shogren K, Giuliani M, Ruesink T, Hefferan TE, Currier BL, Yaszemski MJ (2011) The effects of fixed electrical charge on chondrocyte behavior. Acta Biomater 7: 2080-2090. 
Felka T, Schafer R, Schewe B, Benz K, Aicher WK (2009) Hypoxia reduces the inhibitory effect of IL1beta on chondrogenic differentiation of FCS-free expanded MSC. Osteoarthritis Cartilage 17: 13681376.

Kwon HJ, Yasuda K, Ohmiya Y, Honma K, Chen YM, Gong JP (2010) In vitro differentiation of chondrogenic ATDC5 cells is enhanced by culturing on synthetic hydrogels with various charge densities. Acta Biomater 6: 494-501.
Liu JF, Chen YM, Yang JJ, Kurokawa T, Kakugo A, Yamamoto K, Gong JP (2011) Dynamic behavior and spontaneous differentiation of mouse embryoid bodies on hydrogel substrates of different surface charge and chemical structures. Tissue Eng Part A 17: 2343-2357.

Editor's note: The Scientific Editor responsible for this paper was Mauro Alini. 